\title{
Collision Cross Sections of Charge-Reduced Proteins and Protein Complexes: a Database for CCS Calibration
}

Alyssa Q. Stiving, Benjamin J. Jones, Jakub Ujma, Kevin Giles, Vicki H. Wysocki

\section{Supplementary Information:}

Linear field drift cell pressure recording procedure ...................................................

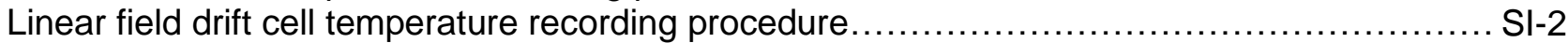

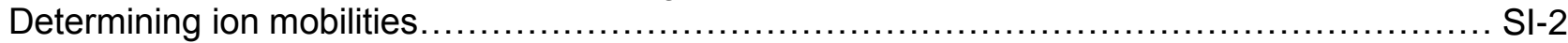

Linear field drift cell CCS data processing procedure .................................................

Calculation of CCS and $\mathrm{K}_{0}$ combined standard uncertainty .......................................

\section{Tables}

Table S1. Standard protein sources...............................................................

Table S2. Synapt G2 Q-IM-TOF instrument parameters prior to IM analysis........................ SI-6

Table S3. Synapt G2 Q-IM-TOF instrument parameters during IM analysis..........................

Table S4. Synapt G2 Q-IM-TOF instrument parameters following IM analysis...................... SI-7

Table S5. Variable instrument tune settings used in linear field drift cell $(\mathrm{He}) \ldots \ldots \ldots \ldots \ldots \ldots \ldots . . .5 \mathrm{SI}-7$

Table S6. Variable instrument tune settings used in linear field drift cell $\left(\mathrm{N}_{2}\right) \ldots \ldots \ldots \ldots \ldots \ldots \ldots . . \mathrm{SI}-8$

Table S7. ${ }^{\mathrm{DT}, 1 \mathrm{ry}} \mathrm{CCS}_{\mathrm{He}}$ and $\mathrm{K}_{\mathrm{o}}$ values for native-like proteins and protein complexes............SI-9-14

Table S8. ${ }^{\mathrm{DT}}$,ry $\mathrm{CCS}_{\mathrm{N} 2}$ and $\mathrm{K}_{0}$ values for native-like proteins and protein complexes...........SI-15-20

Table S9. Experimentally-observed molecular weights for each protein ....................... SI-21-23

Table S10. TWIM calibrants used within Figure S8 ..............................................

\section{Figures}

Figure S1. Location of Baratron and thermocouple............................................ SI-5

Figure S2. lonic strength and $\mathrm{pH}$ comparisons using AmAc/EDDA ........................... SI-24

Figure S3. Representative mass spectrum of BSA 14+ in AmAc/EDDA ..........................

Figure S4. $\triangle$ CCS vs. $\triangle \mathrm{MW}$ for all overlapping charge states..................................

Figure S5. BSA mass spectra and ATDs under varying source conditions …................ SI-27

Figure S6. Weighted-Ko vs. molecular weight for database proteins......................... SI-28

Figure S7. Charge vs. molecular weight for database proteins in nitrogen drift gas.............. SI-29

Figure S8. Error in CCS TWIM calibration using AmAc/TEAA .................................... SI-30

Figure S9. Error in CCS TWIM calibration using AmAc/EDDA …..............................

Figure S10. Representative mass spectra for each protein calibrant.......................SI-32-34

Matlab script used for fitting ATDs to a Gaussian and calculating $\mathrm{K}_{0}$ and CCS values....... SI-35-38

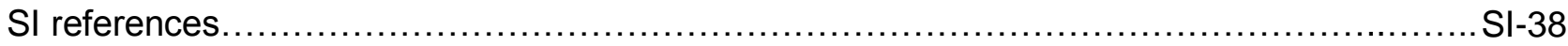




\section{Linear field drift cell pressure recording procedure:}

Pressure recordings were made using an MKS Baratron Type 262 (MKS Instruments Andover, MA) driven by an MKS Type 660 Power Supply (MKS Instruments Andover, MA). Pins 6 and 11 are connected to an ADS1115 16-Bit ADC by Adafruit Industries (New York, NY) which is controlled by an Arduino Uno R3. Pressure measurements were made every 60 seconds and sent over serial to PLX-DAQ (Parallax Inc., Rocklin, CA).

\section{Linear field drift cell temperature recording procedure:}

Temperature measurements were made using an Omega Type K ungrounded thermocouple with \#16 KF flange (Omega Engineering, Inc., Norwalk, CT) and controlled by an Omega i-Series DIN programmable temperature meter with RS232 communications interfaced to VB DAS using iSeries ActiveX Version 2.4.3 to record temperature measurements.

\section{Determining ion mobilities:}

The relationship between drift velocity $\left(V_{D}\right)$ and electric field $(E)$ is governed by the ion's mobility coefficient $(\mathrm{K})$ as outlined in Equation $\mathrm{S} 1$ below:

$$
v_{D}=K E
$$

The mobility, $\mathrm{K}$, is able to provide information regarding the ion-neutral interactions that occur to an ion as it traverses through the buffer gas within the ion mobility cell. ${ }^{9}$ This mobility value $\mathrm{K}$ is more usefully converted into the reduced mobility ( $\mathrm{K}_{0}$, Equation $\mathrm{S} 2$ ) to account for differences in temperature and pressure:

$$
K_{0}=K \cdot \frac{P}{P_{0}} \cdot \frac{T_{0}}{T}
$$

$\mathrm{P}_{0}$ refers to the standard pressure $(1 \mathrm{~atm}=760$ Torr $)$ as commonly used within the $\mathrm{IM}$ community, $T_{0}$ refers to the standard temperature $(273.15 \mathrm{~K})$, and $\mathrm{P}$ and $\mathrm{T}$ correspond to the experimental pressure and temperature, respectively. Experimentally measured arrival times $\left(t_{A}\right.$, Equation S3) include a drift time (to, i.e. the time spent inside the drift cell) and a so-called "dead time" $\left(\mathrm{t}_{0}\right)$, the time spent between the end of the drift cell and the MS detector.

$$
t_{A}=t_{D}+t_{0}
$$

Combining the above equations $\mathrm{S} 1$ and $\mathrm{S} 3$, we obtain:

$$
t_{A}=\frac{1}{K} \cdot \frac{L^{2}}{V}+t_{0}
$$

where $L$ is the length of the drift region. In the IM experiments performed here, the arrival times were measured at different drift voltages. The centroid of each ATD was estimated via fitting to a Gaussian peak function using a Matlab (MathWorks, Natick, MA) script outlined later in the SI. Plotting the experimentally measured arrival times against $P / V$ (where $V$ is drift voltage) results in a linear relationship with a slope of $1 / \mathrm{K}$ and intercept of $t_{0}$. Linear regressions of the data presented here resulted in $R^{2}$ values $\geq 0.9997$.

\section{Linear field drift cell CCS data processing procedure:}

Data was processed through an in-house developed Matlab script in Matlab R2018a (MathWorks, Natick, MA). Briefly, data was imported directly from CSV files created by TWIM Extract ${ }^{1}$ generated from user-defined $\mathrm{m} / \mathrm{z}$ extraction ranges. Ion mobility bias, temperature, and pressure have been added to these CSV files for each instrument data file collected. These drift 
time vs intensity data are then fit to a Gaussian function and the fit results saved to file. The centroid of the Gaussian fit for each drift voltage is plotted against the pressure/drift voltage for each data point and fit to a line. The slope of the resulting fit is used to calculate mobility and CCS as described in the main text. All input and output parameters are written to text file for further analysis.

\section{Calculation of CCS and $K_{0}$ combined standard uncertainty:}

Data was processed through an in-house written Matlab script in Matlab 2018a

(MathWorks, Natick, MA). Pre-fit centroid data was extracted from the output text files of the other Matlab script described above. The slope and slope standard error (SE) were extracted from the model. The uncertainty calculations as outlined in equations S5 and S6 below follow the equations (8) and (10) from Gabelica, et al. (2019). ${ }^{2}$ The factors considered in this uncertainty analysis include the linear fit, temperature measurements, and pressure measurement. Uncertainties in length and reduced mass were not considered. The uncertainties in the Gaussian fits at a 95\% confidence interval were calculated to be $<5 \mu \mathrm{s}$, which is much less than the TOF pusher time and therefore was not included.

$$
\begin{aligned}
& u_{\text {combined }, C C S}=\sqrt{\left(\frac{u_{C C S 1}}{C C S_{1}}\right)^{2}+\left(\frac{u_{C C S 2}}{C C S_{2}}\right)^{2}+\left(\frac{u_{C C S 3}}{C C S_{3}}\right)^{2}+\left(\frac{s t d e v_{C C S}}{C C S_{a v g}}\right)^{2}} \cdot C C S_{a v g} \\
& u_{\text {combined }, K_{0}}=\sqrt{\left(\frac{u_{K_{01}}}{K_{0_{1}}}\right)^{2}+\left(\frac{u_{K_{02}}}{K_{0_{2}}}\right)^{2}+\left(\frac{u_{K_{03}}}{K_{0_{3}}}\right)^{2}+\left(\frac{\text { stdev }_{K_{0}}}{K_{0 \text { avg }}}\right)^{2}} \cdot K_{0 \text { avg }}
\end{aligned}
$$


Table S1. Standard protein sources and additional details.

\begin{tabular}{|c|c|c|c|c|c|}
\hline Protein & symbol & $\begin{array}{c}\text { Molecular } \\
\text { weight } \\
\text { (kDa) }\end{array}$ & Source & Manufacturer & $\begin{array}{c}\text { Part } \\
\text { number }\end{array}$ \\
\hline ubiquitin & UB & 8.5 & $\begin{array}{c}\text { bovine } \\
\text { erythrocytes }\end{array}$ & Sigma Aldrich & U6253 \\
\hline $\begin{array}{l}\beta \text {-lactoglobulin A } \\
\text { (monomer \& dimer) }\end{array}$ & $\begin{array}{l}\text { BLGA1, } \\
\text { BLGA2 }\end{array}$ & $\begin{array}{l}18 \\
36\end{array}$ & bovine milk & Sigma Aldrich & L7880 \\
\hline carbonic anhydrase & $\mathrm{CA}$ & 29 & $\begin{array}{l}\text { bovine } \\
\text { erythrocytes }\end{array}$ & Sigma Aldrich & C2624 \\
\hline streptavidin & SA & 53 & recombinant & Thermo Pierce & 21125 \\
\hline transthyretin & TTR & 56 & human plasma & Sigma Aldrich & P1742 \\
\hline cholera toxin B & CTB & 58 & Vibrio cholera & Sigma Aldrich & C9903 \\
\hline neutravidin & NAV & 60 & egg white & Thermo Scientific & 31000 \\
\hline avidin & $\mathrm{AV}$ & 64 & egg white & Sigma Aldrich & A9275 \\
\hline $\begin{array}{l}\text { bovine serum } \\
\text { albumin }\end{array}$ & BSA & 67 & bovine serum & Sigma Aldrich & A2153 \\
\hline concanavalin A & CON A & 103 & jack bean & Sigma Aldrich & C2010 \\
\hline C-reactive protein & CRP & 115 & $\begin{array}{l}\text { human, } \\
\text { recombinant }\end{array}$ & EMD Millipore & 236608 \\
\hline $\begin{array}{c}\text { alcohol } \\
\text { dehydrogenase }\end{array}$ & $\mathrm{ADH}$ & 147 & $\begin{array}{c}\text { saccharomyces } \\
\text { cerevisiae }\end{array}$ & Sigma Aldrich & A7011 \\
\hline phosphorylase B & PHB & 195 & rabbit muscle & Sigma Aldrich & P6635 \\
\hline pyruvate kinase & PK & 237 & rabbit muscle & Sigma Aldrich & P9136 \\
\hline $\begin{array}{c}\text { glutamate } \\
\text { dehydrogenase }\end{array}$ & GDH & 336 & bovine liver & Sigma Aldrich & G7882 \\
\hline beta-galactosidase & B-GAL & 466 & E. coli & Sigma Aldrich & G5635 \\
\hline glutamine synthetase & GS & 620 & E. coli & Sigma Aldrich & G1270 \\
\hline Gro-EL & GRO-EL & 801 & E. coli & Sigma Aldrich & C7688 \\
\hline
\end{tabular}




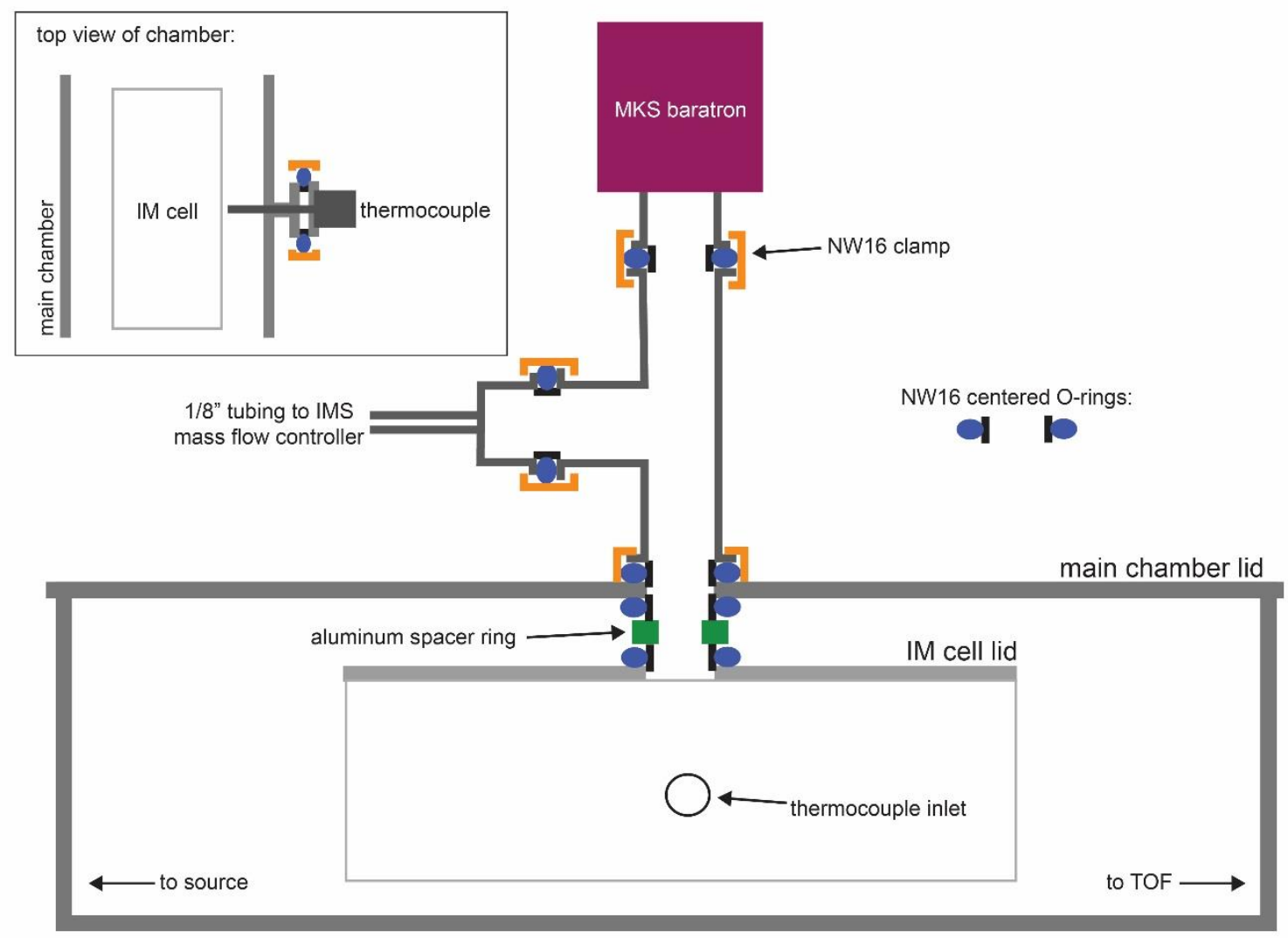

Figure S1. Diagram showing setup and location of Baratron for pressure measurements and thermocouple for temperature measurements used in linear field drift cell IM experiments. A capacitance manometer is used to measure the stabilized pressure within the linear field drift cell. The IM cell top and bottom plates are made of aluminum and are in direct contact with the housing. . The thermocouple touches housing that provides a temperature equal to that of inside the cell. Pressure and temperature measurements recorded at various locations throughout the linear field drift cell and gas "T" were found to be consistent and stable. 
Table S2. Synapt G2 Q-IM-TOF instrument parameters prior to IM analysis. Settings labeled with $a^{*}$ are adjusted based on the protein system and are detailed in Table S5.

\begin{tabular}{lc}
\hline Setting & Value \\
\hline \hline Source temperature & 20 \\
Sampling cone & 20 \\
Extraction cone & 1 \\
Source wave velocity $(\mathrm{m} / \mathrm{s})$ & 313 \\
Source wave height $(\mathrm{V})$ & 6 \\
Trap collision energy & OFF \\
Trap gas flow & $1-10^{*}$ \\
Trap DC entrance & 3 \\
Trap DC bias & 5 \\
Trap DC & 0 \\
Trap DC Exit & 0 \\
Trap wave velocity $(\mathrm{m} / \mathrm{s})$ & 313 \\
Trap wave height $(\mathrm{V})$ & 6 \\
\hline
\end{tabular}

Table S3. Synapt G2 Q-IM-TOF instrument parameters during IM analysis. Settings labeled with an * are adjusted based on the protein system and are detailed in Table S5.

\begin{tabular}{lc}
\hline Setting & Value \\
\hline \hline IM gas flow & $40-150^{*}$ \\
IM DC entrance & -15 \\
Helium cell DC & $70-100^{*}$ \\
Helium exit & -40 \\
IMS bias & $0-200^{*}$ \\
IMS DC exit & 0 \\
IMS wave velocity $(\mathrm{m} / \mathrm{s})$ & 1000 \\
IMS wave height $(\mathrm{V})$ & 0 \\
Mobility trapping release time $(\mu \mathrm{s})$ & 150 \\
Mobility trap height $(\mathrm{V})$ & $5-30^{*}$ \\
Mobility extract height $(\mathrm{V})$ & 0 \\
\hline
\end{tabular}


Table S4. Synapt G2 Q-IM-TOF instrument parameters following IM analysis. Settings labeled as "varies" are adjusted based on the protein system and can be found in Table S5.

\begin{tabular}{lc}
\hline Setting & Value \\
\hline \hline Transfer collision energy & OFF \\
Transfer DC entrance & 5 \\
Transfer DC exit & 0 \\
Transfer wave velocity $(\mathrm{m} / \mathrm{s})$ & 200 \\
Transfer wave height $(\mathrm{V})$ & 4
\end{tabular}

Table S5. Variable instrument tune settings, drift voltages, and IM pressures used in linear field drift cell experiments with He IM gas for establishing ${ }^{\mathrm{DT}, 1 \mathrm{ry}} \mathrm{CCS}_{\mathrm{He}}$ database values.

\begin{tabular}{|c|c|c|c|c|c|c|c|}
\hline Protein & $\begin{array}{l}\text { Trap gas } \\
\text { (mL/min) }\end{array}$ & $\begin{array}{l}\text { IM gas } \\
\text { (mL/min) }\end{array}$ & $\begin{array}{l}\mathrm{He} \\
\text { cell } \\
\mathrm{DC} \\
\end{array}$ & $\begin{array}{c}\text { Mobility } \\
\text { trap } \\
\text { height (V) } \\
\end{array}$ & $\begin{array}{l}\text { IMS } \\
\text { bias }\end{array}$ & $\begin{array}{c}\text { Drift } \\
\text { voltage } \\
\text { (V) } \\
\end{array}$ & $\begin{array}{c}\sim \mathrm{IM} \\
\text { pressure } \\
\text { (torr) } \\
\end{array}$ \\
\hline ubiquitin & 3 & 108 & 100 & 5 & $60-150$ & $1114-202$ & 1.2 \\
\hline$\beta$-lactoglobulin A & 3 & 108 & 100 & 5 & $60-150$ & 114-202 & 1.2 \\
\hline carbonic anhydrase & 3 & 108 & 100 & 5 & $10-100$ & $64-153$ & 1.2 \\
\hline streptavidin & 3 & 150 & 100 & 10 & $20-110$ & $74-163$ & 2.0 \\
\hline transthyretin & 3 & 150 & 100 & 10 & $10-100$ & $64-153$ & 2.0 \\
\hline cholera toxin $B$ & 3 & 150 & 100 & 10 & $110-200$ & $163-252$ & 2.0 \\
\hline neutravidin & 3 & 150 & 100 & 10 & $110-200$ & $163-252$ & 2.0 \\
\hline avidin & 3 & 150 & 100 & 10 & $60-150$ & $114-202$ & 2.0 \\
\hline bovine serum albumin & 3 & 150 & 100 & 10 & $60-150$ & 114-202 & 2.0 \\
\hline concanavalin A & 3 & 150 & 100 & 10 & $30-120$ & $84-173$ & 2.0 \\
\hline C-reactive protein & 3 & 130 & 100 & 10 & $50-140$ & 104-192 & 1.4 \\
\hline alcohol dehydrogenase & 3 & 150 & 100 & 10 & $10-100$ & $64-153$ & 2.0 \\
\hline phosphorylase B & 3 & 150 & 100 & 10 & $10-100$ & $64-153$ & 2.0 \\
\hline pyruvate kinase & 3 & 150 & 100 & 10 & $20-120$ & $74-173$ & 2.0 \\
\hline $\begin{array}{l}\text { glutamate } \\
\text { dehydrogenase }\end{array}$ & 3 & 150 & 100 & 10 & $20-110$ & $74-163$ & 2.0 \\
\hline beta-galactosidase & 10 & 150 & 100 & 10 & $10-100$ & $64-153$ & 2.0 \\
\hline glutamine synthetase & 10 & 80 & 100 & 10 & $0-45$ & $54-99$ & 1.0 \\
\hline GroEL & 10 & 80 & 70 & 30 & $0-45$ & $25-69$ & 1.0 \\
\hline
\end{tabular}


Table S6. Variable instrument tune settings, drift voltages, and IM pressures used in linear field drift cell experiments with $\mathrm{N}_{2}$ IM gas for establishing ${ }^{\mathrm{DT}, 1 \mathrm{ry}} \mathrm{CCS}_{\mathrm{N} 2}$ database values.

\begin{tabular}{lccccccc}
\hline Protein & $\begin{array}{c}\text { Trap gas } \\
\text { flow } \\
\text { (mL/min) }\end{array}$ & $\begin{array}{c}\text { IM gas } \\
\text { flow } \\
\text { (mL/min) }\end{array}$ & $\begin{array}{c}\text { He } \\
\text { cell } \\
\text { DC }\end{array}$ & $\begin{array}{c}\text { Mobility } \\
\text { trap } \\
\text { height (V) }\end{array}$ & $\begin{array}{c}\text { IMS } \\
\text { bias }\end{array}$ & $\begin{array}{c}\text { Drift } \\
\text { voltage } \\
\text { (V) }\end{array}$ & $\begin{array}{c}\text { IM } \\
\text { pressure } \\
\text { (torr) }\end{array}$ \\
\hline \hline ubiquitin & $1-3$ & 60 & 100 & 5 & $60-150$ & $114-202$ & 1.2 \\
B-lactoglobulin A & 3 & 95 & 100 & 5 & $60-150$ & $114-202$ & 2.0 \\
carbonic anhydrase & 3 & 60 & 100 & 5 & $60-150$ & $114-202$ & 1.2 \\
\hline streptavidin & 3 & 95 & 100 & 10 & $110-200$ & $163-252$ & 2.0 \\
transthyretin & 3 & 95 & 100 & 10 & $60-150$ & $114-202$ & 2.0 \\
cholera toxin B & 3 & 95 & 100 & 10 & $60-160$ & $114-202$ & 2.0 \\
\hline neutravidin & 3 & 95 & 100 & 10 & $110-200$ & $163-252$ & 2.0 \\
\hline avidin & 3 & 95 & 100 & 10 & $110-200$ & $163-252$ & 2.0 \\
bovine serum albumin & 3 & 95 & 100 & 10 & $110-200$ & $163-252$ & 2.0 \\
\hline concanavalin A & 3 & 95 & 100 & 10 & $110-200$ & $163-252$ & 2.0 \\
C-reactive protein & 3 & 75 & 100 & 10 & $50-140$ & $104-192$ & 1.4 \\
alcohol dehydrogenase & 3 & 95 & 100 & 10 & $110-200$ & $163-252$ & 2.0 \\
\hline phosphorylase B & 3 & 90 & 100 & 10 & $60-150$ & $114-202$ & 1.6 \\
\hline pyruvate kinase & 3 & 65 & 100 & 10 & $20-140$ & $74-192$ & 1.25 \\
\hline glutamate & 3 & 65 & 100 & 10 & $20-110$ & $74-163$ & 1.25 \\
dehydrogenase & & & & & & & \\
\hline beta-galactosidase & 10 & 40 & 100 & 10 & $0-90$ & $54-143$ & 0.9 \\
\hline glutamine synthetase & 10 & 40 & 100 & 10 & $0-45$ & $54-99$ & 0.9 \\
\hline GroEL & 10 & 50 & 100 & 30 & $15-60$ & $69-114$ & 1.1 \\
\hline & & & & & & & \\
\hline
\end{tabular}


Table S7. ${ }^{\mathrm{DT}, 1 \mathrm{ry}} \mathrm{CCS}_{\mathrm{He}}$ and $\mathrm{K}_{0}$ values for native-like proteins and protein complexes. Abbreviations used: $\mathrm{n}=$ number of subunits in the complex, $\mathrm{z}=$ charge state, $u_{K 0}=$ combined standard uncertainty of the reduced-mobility value, $u_{c c s}=$ combined standard uncertainty of the CCS value.

\begin{tabular}{|c|c|c|c|c|c|c|c|c|c|c|c|c|c|c|c|}
\hline \multirow[b]{2}{*}{ Protein } & \multirow[b]{2}{*}{$\mathbf{n}$} & \multirow[b]{2}{*}{$\begin{array}{c}\text { MW } \\
(\mathrm{kDa})\end{array}$} & \multirow[b]{2}{*}{ z } & \multicolumn{4}{|c|}{ AmAc } & \multicolumn{4}{|c|}{ EDDA } & \multicolumn{4}{|c|}{ TEAA } \\
\hline & & & & $\begin{array}{c}\mathrm{K}_{0} \\
\left(\mathrm{~cm}^{2} /\right. \\
\mathrm{V} \cdot \mathrm{s})\end{array}$ & $\begin{array}{l}\mathrm{u}_{\mathrm{K} 0} \\
(\%)\end{array}$ & $\begin{array}{c}\text { DT,1ry } \mathbf{C} C S_{\mathrm{He}} \\
\left(\AA^{2}\right)\end{array}$ & $\begin{array}{l}u_{c c s} \\
(\%)\end{array}$ & $\begin{array}{c}\mathrm{K}_{0} \\
\left(\mathrm{~cm}^{2} /\right. \\
\mathrm{V} \cdot \mathrm{s})\end{array}$ & $\begin{array}{l}U_{K 0} \\
(\%)\end{array}$ & $\begin{array}{c}\text { DT,1ry } C \text { CCS } \\
\left(\AA_{\mathrm{He}}^{2}\right)\end{array}$ & $\begin{array}{l}\text { Uucs }_{c c s} \\
(\%)\end{array}$ & $\begin{array}{c}\mathrm{K}_{0} \\
\left(\mathrm{~cm}^{2} /\right. \\
\mathrm{V} \cdot \mathrm{s})\end{array}$ & $\begin{array}{l}U_{K 0} \\
(\%)\end{array}$ & $\begin{array}{c}\text { DT,1ry CCS } \\
\left(\AA_{\mathrm{He}}^{2}\right)\end{array}$ & $\begin{array}{l}u_{c c s} \\
(\%)\end{array}$ \\
\hline \multirow[t]{3}{*}{ ubiquitin } & 1 & 8.5 & 3 & - & - & - & - & - & - & - & - & 1.719 & 1.5 & 930 & 1.0 \\
\hline & & & 4 & 2.183 & 1.7 & 980 & 1.2 & 2.224 & 1.4 & 960 & 0.9 & 2.212 & 1.6 & 960 & 1.1 \\
\hline & & & 5 & 2.487 & 1.6 & 1070 & 1.1 & 2.531 & 1.4 & 1060 & 1.0 & - & - & - & - \\
\hline \multirow{4}{*}{$\begin{array}{c}\beta \text {-lacto- } \\
\text { globulin A }\end{array}$} & 1 & 18.3 & 6 & - & - & - & - & - & - & - & - & 1.971 & 1.3 & 1620 & 0.9 \\
\hline & & & 7 & - & - & - & - & 2.265 & 1.5 & 1650 & 1.1 & 2.231 & 1.4 & 1670 & 1.0 \\
\hline & & & 8 & 2.531 & 1.5 & 1690 & 1.2 & 2.489 & 1.8 & 1720 & 1.4 & - & - & - & - \\
\hline & & & 9 & 2.604 & 1.4 & 1850 & 1.0 & - & - & - & - & - & - & - & - \\
\hline \multirow{6}{*}{$\begin{array}{c}\text { carbonic } \\
\text { anhydrase }\end{array}$} & 1 & 29.1 & 6 & - & - & - & - & - & - & - & - & 1.544 & 1.4 & 2080 & 1.0 \\
\hline & & & 7 & - & - & - & - & 1.808 & 1.4 & 2070 & 1.0 & 1.797 & 1.4 & 2080 & 1.0 \\
\hline & & & 8 & 2.048 & 1.6 & 2090 & 1.2 & 2.065 & 1.5 & 2070 & 1.0 & 2.054 & 1.4 & 2080 & 1.0 \\
\hline & & & 9 & 2.291 & 1.5 & 2100 & 1.0 & 2.309 & 1.5 & 2090 & 1.1 & - & - & - & - \\
\hline & & & 10 & 2.515 & 1.4 & 2130 & 0.9 & 2.523 & 1.4 & 2120 & 1.0 & - & - & - & - \\
\hline & & & 11 & 2.704 & 1.5 & 2180 & 1.1 & - & - & - & - & - & - & - & - \\
\hline \multirow{6}{*}{$\begin{array}{c}\beta \text {-lacto- } \\
\text { globulin A }\end{array}$} & 2 & 36.7 & 8 & - & - & - & - & - & - & - & - & 1.595 & 1.5 & 2670 & 1.1 \\
\hline & & & 9 & - & - & - & - & - & - & - & - & 1.787 & 1.5 & 2680 & 1.0 \\
\hline & & & 10 & - & - & - & - & 1.977 & 1.6 & 2700 & 1.1 & - & - & - & - \\
\hline & & & 11 & 2.142 & 1.7 & 2750 & 1.5 & 2.137 & 1.5 & 2750 & 1.0 & - & - & - & - \\
\hline & & & 12 & 2.294 & 1.4 & 2800 & 0.9 & - & - & - & - & - & - & - & - \\
\hline & & & 13 & 2.384 & 1.4 & 2920 & 0.9 & - & - & - & - & - & - & - & - \\
\hline \multirow[t]{7}{*}{ streptavidin } & 4 & 53 & 9 & - & - & - & - & - & - & - & - & 1.444 & 1.3 & 3330 & 0.8 \\
\hline & & & 10 & - & - & - & - & - & - & - & - & 1.609 & 1.3 & 3320 & 0.8 \\
\hline & & & 11 & - & - & - & - & 1.741 & 1.6 & 3370 & 1.3 & 1.767 & 1.3 & 3320 & 0.8 \\
\hline & & & 12 & - & - & - & - & 1.904 & 1.6 & 3360 & 1.3 & - & - & - & - \\
\hline & & & 13 & 2.076 & 1.3 & 3340 & 0.8 & 2.056 & 1.6 & 3370 & 1.3 & - & - & - & - \\
\hline & & & 14 & 2.226 & 1.3 & 3350 & 0.8 & 2.200 & 1.6 & 3400 & 1.2 & - & - & - & - \\
\hline & & & 15 & 2.372 & 1.3 & 3370 & 0.8 & - & - & - & - & - & - & - & - \\
\hline
\end{tabular}




\begin{tabular}{|c|c|c|c|c|c|c|c|c|c|c|c|c|c|c|c|}
\hline \multirow[b]{2}{*}{ Protein } & \multirow[b]{2}{*}{$\mathbf{n}$} & \multirow[b]{2}{*}{$\begin{array}{c}\text { MW } \\
\text { (kDa) }\end{array}$} & \multirow[b]{2}{*}{$\mathbf{z}$} & \multicolumn{4}{|c|}{ AmAc } & \multicolumn{4}{|c|}{ EDDA } & \multicolumn{4}{|c|}{ TEAA } \\
\hline & & & & $\begin{array}{c}\mathrm{K}_{0} \\
\left(\mathrm{~cm}^{2} /\right. \\
\mathrm{V} \cdot \mathrm{s})\end{array}$ & $\begin{array}{l}\mathrm{U}_{\mathrm{K} 0} \\
(\%)\end{array}$ & $\begin{array}{c}\text { DT,1ry } C \text { CCS } \\
\left(\AA_{\mathrm{He}}^{2}\right)\end{array}$ & $\begin{array}{l}\text { Uccs } \\
\text { (\%) }\end{array}$ & $\begin{array}{c}\mathrm{K}_{0} \\
\left(\mathrm{~cm}^{2} /\right. \\
\mathrm{V} \cdot \mathrm{s})\end{array}$ & $\begin{array}{l}U_{K 0} \\
(\%)\end{array}$ & $\begin{array}{c}\text { DT,1ry } C \text { CCS } \\
\left(\AA_{\mathrm{He}}\right) \\
\left(\AA^{2}\right)\end{array}$ & $\begin{array}{l}\text { Uccs } \\
(\%)\end{array}$ & $\begin{array}{c}\mathrm{K}_{0} \\
\left(\mathrm{~cm}^{2} /\right. \\
\mathrm{V} \cdot \mathrm{s})\end{array}$ & $\begin{array}{l}\mathrm{U}_{\mathrm{K} 0} \\
(\%)\end{array}$ & $\begin{array}{c}\text { DT,1ry } C \text { CCS } \\
\left(\AA_{\mathrm{He}}\right) \\
\left(\AA^{2}\right)\end{array}$ & $\begin{array}{c}\text { Uucs }_{\text {ccs }} \\
(\%)\end{array}$ \\
\hline \multirow[t]{6}{*}{ transthyretin } & \multirow[t]{6}{*}{4} & \multirow[t]{6}{*}{56} & 10 & - & - & - & - & - & - & - & - & 1.630 & 1.3 & 3270 & 0.8 \\
\hline & & & 11 & - & - & - & - & - & - & - & - & 1.795 & 1.3 & 3270 & 0.9 \\
\hline & & & 12 & - & - & - & - & 1.930 & 1.4 & 3320 & 1.0 & 1.956 & 1.3 & 3270 & 0.9 \\
\hline & & & 13 & 2.118 & 1.3 & 3270 & 0.8 & 2.086 & 1.3 & 3330 & 0.9 & - & - & - & - \\
\hline & & & 14 & 2.276 & 1.3 & 3280 & 0.8 & 2.235 & 1.4 & 3340 & 0.9 & - & - & - & - \\
\hline & & & 15 & 2.426 & 1.3 & 3300 & 0.8 & - & - & - & - & - & - & - & - \\
\hline \multirow{6}{*}{$\begin{array}{l}\text { cholera } \\
\text { toxin B }\end{array}$} & \multirow[t]{6}{*}{5} & \multirow[t]{6}{*}{58} & 10 & - & - & - & - & - & - & - & - & 1.533 & 1.3 & 3480 & 0.9 \\
\hline & & & 11 & - & - & - & - & - & - & - & - & 1.677 & 1.4 & 3500 & 0.9 \\
\hline & & & 12 & - & - & - & - & - & - & - & - & 1.811 & 1.6 & 3530 & 1.2 \\
\hline & & & 13 & - & - & - & - & 1.963 & 1.3 & 3530 & 0.9 & - & - & - & - \\
\hline & & & 14 & 2.120 & 1.3 & 3520 & 0.8 & 2.109 & 1.3 & 3540 & 0.9 & - & - & - & - \\
\hline & & & 15 & 2.247 & 1.3 & 3560 & 0.9 & 2.237 & 1.5 & 3580 & 1.1 & - & - & - & - \\
\hline \multirow[t]{6}{*}{ neutravidin } & \multirow[t]{6}{*}{4} & \multirow[t]{6}{*}{60} & 11 & - & - & - & - & - & - & - & - & 1.722 & 1.5 & 3420 & 1.1 \\
\hline & & & 12 & - & - & - & - & - & - & - & - & 1.865 & 1.5 & 3440 & 1.1 \\
\hline & & & 13 & - & - & - & - & 1.957 & 1.7 & 3550 & 1.4 & - & - & - & - \\
\hline & & & 14 & 2.162 & 1.3 & 3460 & 0.9 & 2.109 & 1.7 & 3550 & 1.3 & - & - & - & - \\
\hline & & & 15 & 2.318 & 1.4 & 3460 & 0.9 & 2.264 & 1.7 & 3550 & 1.3 & - & - & - & - \\
\hline & & & 16 & 2.462 & 1.5 & 3480 & 1.0 & - & - & - & - & - & - & - & - \\
\hline \multirow[t]{8}{*}{ avidin } & \multirow[t]{8}{*}{4} & \multirow[t]{8}{*}{64} & 10 & - & - & - & - & - & - & - & - & 1.523 & 1.9 & 3500 & 1.5 \\
\hline & & & 11 & - & - & - & - & - & - & - & - & 1.690 & 1.4 & 3470 & 0.9 \\
\hline & & & 12 & - & - & - & - & - & - & - & - & 1.838 & 1.3 & 3480 & 0.8 \\
\hline & & & 13 & - & - & - & - & 1.973 & 1.6 & 3510 & 1.2 & 1.981 & 1.5 & 3500 & 1.1 \\
\hline & & & 14 & 2.163 & 1.4 & 3460 & 0.9 & 2.129 & 1.7 & 3500 & 1.2 & - & - & - & - \\
\hline & & & 15 & 2.332 & 1.4 & 3440 & 1.0 & 2.278 & 1.7 & 3510 & 1.3 & - & - & - & - \\
\hline & & & 16 & 2.483 & 1.4 & 3440 & 1.0 & 2.419 & 1.9 & 3520 & 1.5 & - & - & - & - \\
\hline & & & 17 & 2.633 & 1.5 & 3450 & 1.2 & - & - & - & - & - & - & - & - \\
\hline
\end{tabular}




\begin{tabular}{|c|c|c|c|c|c|c|c|c|c|c|c|c|c|c|c|}
\hline \multirow[b]{2}{*}{ Protein } & \multirow[b]{2}{*}{$\mathbf{n}$} & \multirow[b]{2}{*}{$\begin{array}{c}\text { MW } \\
\text { (kDa) }\end{array}$} & \multirow[b]{2}{*}{$\mathbf{z}$} & \multicolumn{4}{|c|}{ AmAc } & \multicolumn{4}{|c|}{ EDDA } & \multicolumn{4}{|c|}{ TEAA } \\
\hline & & & & $\begin{array}{c}\mathrm{K}_{0} \\
\left(\mathrm{~cm}^{2} /\right. \\
\mathrm{V} \cdot \mathrm{s})\end{array}$ & $\begin{array}{l}\mathrm{U}_{\mathrm{K} 0} \\
(\%)\end{array}$ & $\begin{array}{c}\text { DT,1ry } \mathrm{CCS}_{\mathrm{He}} \\
\left(\AA^{2}\right)\end{array}$ & $\begin{array}{l}u_{c c s} \\
(\%)\end{array}$ & $\begin{array}{c}\mathrm{K}_{0} \\
\left(\mathrm{~cm}^{2} /\right. \\
\mathrm{V} \cdot \mathrm{s})\end{array}$ & $\begin{array}{l}u_{K 0} \\
(\%)\end{array}$ & $\begin{array}{c}\text { DT,1ry } \mathrm{CCS}_{\mathrm{He}} \\
\left(\AA^{2}\right)\end{array}$ & $\begin{array}{l}\text { Uccs } \\
(\%)\end{array}$ & $\begin{array}{c}\mathrm{K}_{0} \\
\left(\mathrm{~cm}^{2} /\right. \\
\mathrm{V} \cdot \mathrm{s})\end{array}$ & $\begin{array}{l}\mathrm{u}_{\mathrm{K} 0} \\
(\%)\end{array}$ & $\begin{array}{c}\text { DT,1ry } \mathrm{CCS}_{\mathrm{He}} \\
\left(\mathrm{A}^{2}\right)\end{array}$ & $\begin{array}{l}u_{c c s} \\
(\%)\end{array}$ \\
\hline \multirow{8}{*}{$\begin{array}{l}\text { bovine } \\
\text { serum } \\
\text { albumin }\end{array}$} & \multirow[t]{8}{*}{1} & \multirow[t]{8}{*}{66} & 10 & - & - & - & - & - & - & - & - & 1.368 & 1.8 & 3900 & 1.5 \\
\hline & & & 11 & - & - & - & - & - & - & - & - & 1.496 & 1.3 & 3920 & 0.9 \\
\hline & & & 12 & - & - & - & - & - & - & - & - & 1.620 & 1.3 & 3950 & 0.9 \\
\hline & & & 13 & - & - & - & - & 1.728 & 1.5 & 4010 & 1.0 & 1.745 & 1.4 & 3970 & 0.9 \\
\hline & & & 14 & 1.931 & 1.4 & 3880 & 1.1 & 1.844 & 1.4 & 4050 & 0.9 & - & - & - & - \\
\hline & & & 15 & 2.048 & 1.6 & 3920 & 1.2 & 1.956 & 1.5 & 4090 & 0.9 & - & - & - & - \\
\hline & & & 16 & 2.169 & 1.5 & 3940 & 1.1 & - & - & - & - & - & - & - & - \\
\hline & & & 17 & 2.280 & 1.8 & 3990 & 1.4 & - & - & - & - & - & - & - & - \\
\hline \multirow{8}{*}{$\begin{array}{c}\text { concanavalin } \\
\text { A }\end{array}$} & \multirow[t]{8}{*}{4} & \multirow[t]{8}{*}{103} & 13 & - & - & - & - & - & - & - & - & 1.290 & 1.3 & 5360 & 0.8 \\
\hline & & & 14 & - & - & - & - & - & - & - & - & 1.391 & 1.3 & 5350 & 0.8 \\
\hline & & & 15 & - & - & - & - & - & - & - & - & 1.490 & 1.3 & 5350 & 0.8 \\
\hline & & & 16 & - & - & - & - & 1.569 & 1.6 & 5440 & 1.3 & - & - & - & - \\
\hline & & & 17 & - & - & - & - & 1.666 & 1.6 & 5440 & 1.2 & - & - & - & - \\
\hline & & & 18 & 1.812 & 1.5 & 5320 & 1.1 & 1.763 & 1.5 & 5440 & 1.1 & - & - & - & - \\
\hline & & & 19 & 1.914 & 1.5 & 5310 & 1.2 & - & - & - & - & - & - & - & - \\
\hline & & & 20 & 2.015 & 1.5 & 5310 & 1.1 & - & - & - & - & - & - & - & - \\
\hline \multirow{11}{*}{$\begin{array}{c}\text { C-reactive } \\
\text { protein }\end{array}$} & \multirow[t]{11}{*}{5} & \multirow[t]{11}{*}{115} & 16 & - & - & - & - & - & - & - & - & 1.332 & 1.5 & 6400 & 1.1 \\
\hline & & & 17 & - & - & - & - & - & - & - & - & 1.411 & 1.3 & 6420 & 0.9 \\
\hline & & & 18 & - & - & - & - & - & - & - & - & 1.493 & 1.3 & 6420 & 0.9 \\
\hline & & & 19 & - & - & - & - & 1.598 & 1.6 & 6340 & 1.2 & 1.570 & 1.3 & 6450 & 0.9 \\
\hline & & & 20 & - & - & - & - & 1.678 & 1.7 & 6360 & 1.2 & - & - & - & - \\
\hline & & & 21 & - & - & - & - & 1.757 & 1.6 & 6380 & 1.1 & - & - & - & - \\
\hline & & & 22 & - & - & - & - & 1.828 & 1.4 & 6420 & 0.9 & - & - & - & - \\
\hline & & & 23 & 1.906 & 1.4 & 6430 & 0.9 & 1.898 & 1.6 & 6470 & 1.1 & - & - & - & - \\
\hline & & & 24 & 1.980 & 1.3 & 6460 & 0.9 & - & - & - & - & - & - & - & - \\
\hline & & & 25 & 2.057 & 1.4 & 6470 & 0.9 & - & - & - & - & - & - & - & - \\
\hline & & & 26 & 2.123 & 1.4 & 6530 & 0.9 & - & - & - & - & - & - & - & - \\
\hline
\end{tabular}




\begin{tabular}{|c|c|c|c|c|c|c|c|c|c|c|c|c|c|c|c|}
\hline \multirow[b]{2}{*}{ Protein } & \multirow[b]{2}{*}{$\mathbf{n}$} & \multirow[b]{2}{*}{$\begin{array}{c}\text { MW } \\
\text { (kDa) }\end{array}$} & \multirow[b]{2}{*}{$\mathbf{z}$} & \multicolumn{4}{|c|}{ AmAc } & \multicolumn{4}{|c|}{ EDDA } & \multicolumn{4}{|c|}{ TEAA } \\
\hline & & & & $\begin{array}{c}\mathrm{K}_{0} \\
\left(\mathrm{~cm}^{2} /\right. \\
\mathrm{V} \cdot \mathrm{s})\end{array}$ & $\begin{array}{l}\mathrm{U}_{\mathrm{K} 0} \\
(\%)\end{array}$ & $\begin{array}{c}\text { DT,1ry } \mathrm{CCS}_{\mathrm{He}} \\
\left(\AA^{2}\right)\end{array}$ & $\begin{array}{l}\mathbf{u}_{\mathrm{ccs}} \\
(\%)\end{array}$ & $\begin{array}{c}\mathrm{K}_{0} \\
\left(\mathrm{~cm}^{2} /\right. \\
\mathrm{V} \cdot \mathrm{s})\end{array}$ & $\begin{array}{l}U_{K 0} \\
(\%)\end{array}$ & $\begin{array}{c}\text { DT,1ry } \mathrm{CCS}_{\mathrm{He}} \\
\left(\AA^{2}\right)\end{array}$ & $\begin{array}{l}\text { Uccs } \\
(\%)\end{array}$ & $\begin{array}{c}\mathrm{K}_{0} \\
\left(\mathrm{~cm}^{2} /\right. \\
\mathrm{V} \cdot \mathrm{s})\end{array}$ & $\begin{array}{l}U_{K 0} \\
(\%)\end{array}$ & $\begin{array}{c}\text { DT,1ry } \mathrm{CCS}_{\mathrm{He}} \\
\left(\AA^{2}\right)\end{array}$ & $\begin{array}{l}\text { Uccs } \\
(\%)\end{array}$ \\
\hline \multirow{9}{*}{$\begin{array}{c}\text { alcohol } \\
\text { dehydrogenase }\end{array}$} & \multirow[t]{9}{*}{4} & \multirow[t]{9}{*}{147} & 17 & - & - & - & - & - & - & - & - & 1.323 & 1.4 & 6850 & 1.1 \\
\hline & & & 18 & - & - & - & - & - & - & - & - & 1.404 & 1.5 & 6830 & 1.2 \\
\hline & & & 19 & - & - & - & - & - & - & - & - & 1.484 & 1.6 & 6830 & 1.3 \\
\hline & & & 20 & - & - & - & - & 1.545 & 1.7 & 6890 & 1.3 & - & - & - & - \\
\hline & & & 21 & - & - & - & - & 1.614 & 1.3 & 6930 & 0.8 & - & - & - & - \\
\hline & & & 22 & - & - & - & - & 1.688 & 1.3 & 6940 & 0.8 & - & - & - & - \\
\hline & & & 23 & 1.865 & 1.4 & 6590 & 1.0 & 1.758 & 1.3 & 6960 & 0.8 & - & - & - & - \\
\hline & & & 24 & 1.942 & 1.3 & 6610 & 0.9 & - & - & - & - & - & - & - & - \\
\hline & & & 25 & 2.039 & 1.6 & 6560 & 1.3 & - & - & - & - & - & - & - & - \\
\hline \multirow{11}{*}{$\begin{array}{c}\text { phosphorylase } \\
\text { B }\end{array}$} & \multirow[t]{11}{*}{2} & \multirow[t]{11}{*}{195} & 20 & - & - & - & - & - & - & - & - & 1.244 & 1.4 & 8560 & 1.0 \\
\hline & & & 21 & - & - & - & - & - & - & - & - & 1.305 & 1.4 & 8570 & 1.0 \\
\hline & & & 22 & - & - & - & - & - & - & - & - & 1.368 & 1.5 & 8560 & 1.1 \\
\hline & & & 23 & - & - & - & - & 1.418 & 1.4 & 8630 & 1.0 & - & - & - & - \\
\hline & & & 24 & - & - & - & - & 1.478 & 1.4 & 8650 & 1.1 & - & - & - & - \\
\hline & & & 25 & - & - & - & - & 1.536 & 1.4 & 8670 & 1.1 & - & - & - & - \\
\hline & & & 26 & 1.608 & 1.3 & 8600 & 0.9 & 1.593 & 1.4 & 8690 & 1.0 & - & - & - & - \\
\hline & & & 27 & 1.664 & 1.3 & 8630 & 0.9 & 1.648 & 1.5 & 8730 & 1.2 & - & - & - & - \\
\hline & & & 28 & 1.722 & 1.3 & 8650 & 0.9 & - & - & - & - & - & - & - & - \\
\hline & & & 29 & 1.780 & 1.3 & 8670 & 0.9 & - & - & - & - & - & - & - & - \\
\hline & & & 30 & 1.832 & 1.4 & 8710 & 1.0 & - & - & - & - & - & - & - & - \\
\hline \multirow{10}{*}{$\begin{array}{l}\text { pyruvate } \\
\text { kinase }\end{array}$} & \multirow[t]{10}{*}{4} & \multirow[t]{10}{*}{237} & 23 & - & - & - & - & - & - & - & - & 1.237 & 1.4 & 9920 & 1.0 \\
\hline & & & 24 & - & - & - & - & - & - & - & - & 1.286 & 1.3 & 9960 & 0.9 \\
\hline & & & 25 & - & - & - & - & - & - & - & - & 1.339 & 1.4 & 9960 & 1.0 \\
\hline & & & 28 & - & - & - & - & - & - & - & - & - & - & - & - \\
\hline & & & 29 & - & - & - & - & 1.528 & 1.7 & 10100 & 1.3 & - & - & - & - \\
\hline & & & 30 & - & - & - & - & 1.585 & 1.5 & 10080 & 1.1 & - & - & - & - \\
\hline & & & 31 & 1.684 & 1.3 & 9830 & 0.9 & 1.631 & 1.4 & 10110 & 1.0 & - & - & - & - \\
\hline & & & 32 & 1.729 & 1.3 & 9890 & 0.8 & - & - & - & - & - & - & - & - \\
\hline & & & 33 & 1.781 & 1.3 & 9890 & 0.8 & - & - & - & - & - & - & - & - \\
\hline & & & 34 & 1.836 & 1.3 & 9890 & 0.8 & - & - & - & - & - & - & - & - \\
\hline
\end{tabular}




\begin{tabular}{|c|c|c|c|c|c|c|c|c|c|c|c|c|c|c|c|}
\hline \multirow[b]{2}{*}{ Protein } & \multirow[b]{2}{*}{$\mathbf{n}$} & \multirow[b]{2}{*}{$\begin{array}{c}\text { MW } \\
\text { (kDa) }\end{array}$} & \multirow[b]{2}{*}{$\mathbf{z}$} & \multicolumn{4}{|c|}{ AmAc } & \multicolumn{4}{|c|}{ EDDA } & \multicolumn{4}{|c|}{ TEAA } \\
\hline & & & & $\begin{array}{c}\mathrm{K}_{0} \\
\left(\mathrm{~cm}^{2} /\right. \\
\mathrm{V} \cdot \mathrm{s}) \\
\end{array}$ & $\begin{array}{l}U_{K 0} \\
(\%)\end{array}$ & $\begin{array}{c}\text { DT,1ry } \mathrm{CCS}_{\mathrm{He}} \\
\left(\AA^{2}\right)\end{array}$ & $\begin{array}{l}u_{c c s} \\
(\%)\end{array}$ & $\begin{array}{c}\mathrm{K}_{0} \\
\left(\mathrm{~cm}^{2} /\right. \\
\mathrm{V} \cdot \mathrm{s})\end{array}$ & $\begin{array}{l}U_{K 0} \\
(\%)\end{array}$ & $\begin{array}{c}\text { DT,1ry } \mathrm{C} \mathrm{CS}_{\mathrm{He}} \\
\left(\AA^{2}\right)\end{array}$ & $\begin{array}{l}\text { Uccs }_{\text {ccs }} \\
(\%)\end{array}$ & $\begin{array}{c}\mathrm{K}_{0} \\
\left(\mathrm{~cm}^{2} /\right. \\
\mathrm{V} \cdot \mathrm{s}) \\
\end{array}$ & $\begin{array}{l}u_{K 0} \\
(\%)\end{array}$ & $\begin{array}{c}\text { DT,1ry } \mathrm{CCS}_{\mathrm{He}} \\
\left(\AA^{2}\right)\end{array}$ & $\begin{array}{l}\text { Uccs } \\
(\%)\end{array}$ \\
\hline \multirow{11}{*}{$\begin{array}{c}\text { glutamate } \\
\text { dehydrogenase }\end{array}$} & \multirow[t]{11}{*}{6} & \multirow[t]{11}{*}{336} & 26 & - & - & - & - & - & - & - & - & 1.165 & 1.6 & 11890 & 1.2 \\
\hline & & & 27 & - & - & - & - & - & - & - & - & 1.209 & 1.4 & 11890 & 1.0 \\
\hline & & & 28 & - & - & - & - & - & - & - & - & 1.257 & 1.4 & 11860 & 1.0 \\
\hline & & & 29 & - & - & - & - & - & - & - & - & - & - & - & - \\
\hline & & & 31 & - & - & - & - & 1.416 & 1.5 & 11670 & 1.1 & - & - & - & - \\
\hline & & & 32 & - & - & - & - & 1.465 & 1.5 & 11650 & 1.2 & - & - & - & - \\
\hline & & & 33 & - & - & - & - & 1.509 & 1.5 & 11660 & 1.1 & - & - & - & - \\
\hline & & & 35 & 1.565 & 1.5 & 11950 & 1.1 & - & - & - & - & - & - & - & - \\
\hline & & & 36 & 1.592 & 1.5 & 12080 & 1.1 & - & - & - & - & - & - & - & - \\
\hline & & & 37 & 1.626 & 1.5 & 12160 & 1.2 & - & - & - & - & - & - & - & - \\
\hline & & & 38 & 1.664 & 1.6 & 12200 & 1.3 & - & - & - & - & - & - & - & - \\
\hline \multirow{9}{*}{$\begin{array}{c}\text { Beta- } \\
\text { galactosidase }\end{array}$} & \multirow[t]{9}{*}{4} & \multirow[t]{9}{*}{466} & 32 & - & - & - & - & - & - & - & - & 1.203 & 1.5 & 14240 & 1.1 \\
\hline & & & 33 & - & - & - & - & - & - & - & - & 1.233 & 1.4 & 14330 & 0.9 \\
\hline & & & 34 & - & - & - & - & - & - & - & - & 1.271 & 1.3 & 14320 & 0.9 \\
\hline & & & 35 & - & - & - & - & - & - & - & - & 1.308 & 1.4 & 14320 & 1.0 \\
\hline & & & 44 & 1.555 & 1.6 & 15150 & 1.2 & - & - & - & - & - & - & - & - \\
\hline & & & 45 & 1.588 & 1.8 & 15170 & 1.5 & - & - & - & - & - & - & - & - \\
\hline & & & 46 & 1.613 & 1.6 & 15260 & 1.3 & - & - & - & - & - & - & - & - \\
\hline & & & 47 & 1.652 & 1.5 & 15230 & 1.1 & - & - & - & - & - & - & - & - \\
\hline & & & 48 & 1.690 & 1.7 & 15200 & 1.4 & - & - & - & - & - & - & - & - \\
\hline
\end{tabular}




\begin{tabular}{|c|c|c|c|c|c|c|c|c|c|c|c|c|c|c|c|}
\hline \multirow[b]{2}{*}{ Protein } & \multirow[b]{2}{*}{$\mathbf{n}$} & \multirow[b]{2}{*}{$\begin{array}{c}\text { MW } \\
(k D a)\end{array}$} & \multirow[b]{2}{*}{$\mathbf{z}$} & \multicolumn{4}{|c|}{ AmAc } & \multicolumn{4}{|c|}{ EDDA } & \multicolumn{4}{|c|}{ TEAA } \\
\hline & & & & $\begin{array}{c}\mathrm{K}_{0} \\
\left(\mathrm{~cm}^{2} /\right. \\
\mathrm{V} \cdot \mathbf{s})\end{array}$ & $\begin{array}{l}\mathrm{U}_{\mathrm{K} 0} \\
(\%)\end{array}$ & $\begin{array}{c}\mathrm{DT}, 1 \mathrm{ry} C \mathrm{C} \mathrm{S}_{\mathrm{He}} \\
\left(\AA^{2}\right)\end{array}$ & $\begin{array}{c}\text { Uccs } \\
(\%)\end{array}$ & $\begin{array}{c}\mathrm{K}_{0} \\
\left(\mathrm{~cm}^{2} /\right. \\
\mathrm{V} \cdot \mathbf{s})\end{array}$ & $\begin{array}{l}\mathrm{U}_{\mathrm{K} 0} \\
(\%)\end{array}$ & $\begin{array}{c}\text { DT,1ry CC. } S_{\mathrm{He}} \\
\left(\AA^{2}\right)\end{array}$ & $\begin{array}{l}\text { Uccs } \\
(\%)\end{array}$ & $\begin{array}{c}\mathrm{K}_{0} \\
\left(\mathrm{~cm}^{2} /\right. \\
\mathrm{V} \cdot \mathrm{s})\end{array}$ & $\begin{array}{l}\mathrm{U}_{\mathrm{K} 0} \\
(\%)\end{array}$ & $\begin{array}{c}\text { DT,1ry CCS } \\
\left(\AA^{2}\right)\end{array}$ & $\begin{array}{c}\text { Uccs } \\
(\%)\end{array}$ \\
\hline glutamine & 12 & 620.2 & 34 & - & - & - & - & - & - & - & - & 1.058 & 1.6 & 17210 & 1.3 \\
\hline \multirow[t]{16}{*}{ synthetase } & & & 35 & - & - & - & - & - & - & - & - & 1.093 & 1.6 & 17160 & 1.2 \\
\hline & & & 36 & - & - & - & - & - & - & - & - & 1.132 & 1.5 & 17030 & 1.1 \\
\hline & & & 37 & - & - & - & - & - & - & - & - & 1.174 & 1.5 & 16880 & 1.1 \\
\hline & & & 38 & - & - & - & - & - & - & - & - & 1.207 & 1.4 & 16860 & 1.0 \\
\hline & & & 39 & - & - & - & - & 1.265 & 1.6 & 16510 & 1.3 & - & - & - & - \\
\hline & & & 40 & - & - & - & - & 1.298 & 1.6 & 16510 & 1.2 & - & - & - & - \\
\hline & & & 41 & - & - & - & - & 1.334 & 1.4 & 16460 & 1.0 & - & - & - & - \\
\hline & & & 42 & - & - & - & - & 1.372 & 1.4 & 16390 & 0.9 & - & - & - & - \\
\hline & & & 43 & - & - & - & - & 1.405 & 1.4 & 16390 & 0.9 & - & - & - & - \\
\hline & & & 44 & - & - & - & - & 1.418 & 1.5 & 16610 & 1.1 & - & - & - & - \\
\hline & & & 50 & 1.635 & 1.6 & 16370 & 1.3 & - & - & - & - & - & - & - & - \\
\hline & & & 51 & 1.654 & 1.4 & 16510 & 1.0 & - & - & - & - & - & - & - & - \\
\hline & & & 52 & 1.678 & 1.4 & 16600 & 0.9 & - & - & - & - & - & - & - & - \\
\hline & & & 53 & 1.710 & 1.3 & 16600 & 0.9 & - & - & - & - & - & - & - & - \\
\hline & & & 54 & 1.745 & 1.3 & 16570 & 0.8 & - & - & - & - & - & - & - & - \\
\hline & & & 55 & 1.775 & 1.3 & 16590 & 0.9 & - & - & - & - & - & - & - & - \\
\hline \multirow[t]{6}{*}{ GroEL } & 12 & 801 & 45 & - & - & - & - & - & - & - & - & 1.321 & 1.5 & 18240 & 1.1 \\
\hline & & & 46 & - & - & - & - & - & - & - & - & 1.346 & 1.5 & 18300 & 1.1 \\
\hline & & & 47 & - & - & - & - & - & - & - & - & 1.380 & 1.5 & 18240 & 1.1 \\
\hline & & & 48 & - & - & - & - & - & - & - & - & 1.414 & 1.4 & 18170 & 1.0 \\
\hline & & & 49 & - & - & - & - & - & - & - & - & 1.447 & 1.4 & 18130 & 0.9 \\
\hline & & & 50 & - & - & - & - & - & - & - & - & 1.480 & 1.6 & 18090 & 1.2 \\
\hline
\end{tabular}


Table S8. ${ }^{\mathrm{DT}, 1 \mathrm{ry}} \mathrm{CCS}_{\mathrm{N} 2}$ and $\mathrm{K}_{0}$ values for native-like proteins and protein complexes. Abbreviations used: $\mathrm{n}=\mathrm{number}$ of subunits in the complex, $\mathrm{z}=$ charge state, $u_{k 0}=$ combined standard uncertainty of the reduced-mobility value, $u_{c c s}=$ combined standard uncertainty of the CCS value.

\begin{tabular}{|c|c|c|c|c|c|c|c|c|c|c|c|c|c|c|c|}
\hline \multirow[b]{2}{*}{ Protein } & \multirow[b]{2}{*}{$\mathbf{n}$} & \multirow[b]{2}{*}{$\begin{array}{l}\text { MW } \\
\text { (kDa) }\end{array}$} & \multirow[b]{2}{*}{$\mathbf{z}$} & \multicolumn{4}{|c|}{ AmAc } & \multicolumn{4}{|c|}{ EDDA } & \multicolumn{4}{|c|}{ TEAA } \\
\hline & & & & $\begin{array}{c}\mathrm{K}_{0} \\
\left(\mathrm{~cm}^{2} /\right. \\
\mathrm{V} \cdot \mathrm{s})\end{array}$ & $\begin{array}{l}\mathrm{u}_{\mathrm{K} 0} \\
(\%)\end{array}$ & $\begin{array}{c}\text { DT,1ry } C \text { CCS } \\
\left(\AA_{\mathrm{N} 2}^{2}\right)\end{array}$ & $\begin{array}{c}\text { Uucs }_{\text {ccs }} \\
(\%)\end{array}$ & $\begin{array}{c}\mathrm{K}_{0} \\
\left(\mathrm{~cm}^{2} /\right. \\
\mathrm{V} \cdot \mathrm{s})\end{array}$ & $\begin{array}{l}U_{K 0} \\
(\%)\end{array}$ & $\begin{array}{c}\text { DT,1ry } C C S_{N 2} \\
\left(\AA^{2}\right)\end{array}$ & $\begin{array}{l}U_{c c s} \\
(\%)\end{array}$ & $\begin{array}{c}\mathrm{K}_{0} \\
\left(\mathrm{~cm}^{2} /\right. \\
\mathrm{V} \cdot \mathrm{s})\end{array}$ & $\begin{array}{l}U_{K 0} \\
(\%)\end{array}$ & $\begin{array}{c}\text { DT,1ry } C \text { CS } S_{\mathrm{N} 2} \\
\left(\AA^{2}\right)\end{array}$ & $\begin{array}{c}\text { Uccs } \\
(\%)\end{array}$ \\
\hline \multirow[t]{3}{*}{ ubiquitin } & \multirow[t]{3}{*}{1} & \multirow[t]{3}{*}{8.5} & 4 & 0.686 & 1.4 & 1180 & 1.0 & 0.689 & 1.5 & 1170 & 1.1 & 0.685 & 1.6 & 1180 & 1.2 \\
\hline & & & 5 & 0.769 & 1.5 & 1310 & 1.1 & 0.758 & 1.3 & 1330 & 0.9 & 0.760 & 1.4 & 1330 & 1.0 \\
\hline & & & 6 & 0.701 & 1.3 & 1730 & 0.8 & - & - & - & - & 0.695 & 1.4 & 1750 & 1.0 \\
\hline \multirow{2}{*}{$\begin{array}{c}\beta \text {-lacto- } \\
\text { globulin A }\end{array}$} & \multirow[t]{2}{*}{1} & \multirow[t]{2}{*}{18.3} & 7 & - & - & - & - & 0.731 & 1.6 & 1930 & 1.1 & 0.725 & 1.4 & 1950 & 1.0 \\
\hline & & & 8 & 0.776 & 1.5 & 2080 & 1.1 & - & - & - & - & - & - & - & - \\
\hline \multirow{6}{*}{$\begin{array}{c}\text { carbonic } \\
\text { anhydrase }\end{array}$} & \multirow[t]{6}{*}{1} & \multirow[t]{6}{*}{29.1} & 5 & - & - & - & - & - & - & - & - & 0.520 & 1 & 1950 & 1.0 \\
\hline & & & 6 & - & - & - & - & - & - & - & - & 0.508 & 1 & 2390 & 0.8 \\
\hline & & & 7 & - & - & - & - & 0.587 & 1.3 & 2420 & 0.9 & 0.587 & 1 & 2410 & 0.8 \\
\hline & & & 8 & 0.662 & 1.5 & 2450 & 1.0 & 0.662 & 1.4 & 2450 & 0.9 & 0.666 & 1 & 2430 & 0.8 \\
\hline & & & 9 & 0.736 & 1.4 & 2480 & 0.9 & 0.737 & 1.3 & 2470 & 0.9 & - & - & - & - \\
\hline & & & 10 & 0.804 & 1.4 & 2520 & 0.9 & 0.805 & 1.3 & 2520 & 0.9 & - & - & - & - \\
\hline \multirow{4}{*}{$\begin{array}{c}\beta \text {-lacto- } \\
\text { globulin A }\end{array}$} & \multirow[t]{4}{*}{2} & \multirow[t]{4}{*}{36.7} & 8 & - & - & - & - & - & - & - & - & 0.534 & 1.4 & 3020 & 0.9 \\
\hline & & & 9 & - & - & - & - & - & - & - & - & 0.594 & 1.3 & 3060 & 0.9 \\
\hline & & & 10 & - & - & - & - & 0.648 & 1.5 & 3120 & 1.1 & - & - & - & - \\
\hline & & & 11 & 0.692 & 1.3 & 3210 & 0.9 & 0.696 & 1.5 & 3190 & 1.0 & - & - & - & - \\
\hline \multirow[t]{6}{*}{ streptavidin } & \multirow[t]{6}{*}{4} & \multirow[t]{6}{*}{53} & 10 & - & - & - & - & - & - & - & - & 0.544 & 1.6 & 3730 & 1.2 \\
\hline & & & 11 & - & - & - & - & - & - & - & - & 0.594 & 1.5 & 3760 & 1.1 \\
\hline & & & 12 & - & - & - & - & 0.645 & 1.7 & 3770 & 1.1 & 0.642 & 1.5 & 3800 & 1.1 \\
\hline & & & 13 & 0.684 & 1.6 & 3840 & 1.0 & 0.691 & 1.5 & 3810 & 1.0 & - & - & - & - \\
\hline & & & 14 & 0.732 & 1.5 & 3870 & 0.9 & 0.739 & 1.6 & 3840 & 1.0 & - & - & - & - \\
\hline & & & 15 & 0.779 & 1.5 & 3890 & 0.9 & - & - & - & - & - & - & - & - \\
\hline
\end{tabular}




\begin{tabular}{|c|c|c|c|c|c|c|c|c|c|c|c|c|c|c|c|}
\hline \multirow[b]{2}{*}{ Protein } & \multirow[b]{2}{*}{$\mathbf{n}$} & \multirow[b]{2}{*}{$\begin{array}{c}\text { MW } \\
\text { (kDa) }\end{array}$} & \multirow[b]{2}{*}{$\mathbf{z}$} & \multicolumn{4}{|c|}{ AmAc } & \multicolumn{4}{|c|}{ EDDA } & \multicolumn{4}{|c|}{ TEAA } \\
\hline & & & & $\begin{array}{c}\mathrm{K}_{0} \\
\left(\mathrm{~cm}^{2} /\right. \\
\mathrm{V} \cdot \mathrm{s})\end{array}$ & $\begin{array}{l}U_{K 0} \\
(\%)\end{array}$ & $\begin{array}{c}\text { DT,1ry } \mathrm{C} \mathrm{CS} \mathrm{S}_{\mathrm{N} 2} \\
\left(\AA^{2}\right)\end{array}$ & $\begin{array}{c}u_{\text {ccs }} \\
(\%)\end{array}$ & $\begin{array}{c}\mathrm{K}_{0} \\
\left(\mathrm{~cm}^{2} /\right. \\
\mathrm{V} \cdot \mathrm{s})\end{array}$ & $\begin{array}{l}U_{K 0} \\
(\%)\end{array}$ & $\begin{array}{c}\text { DT,1ry } \mathbf{C O C S}_{\mathrm{N} 2} \\
\left(\AA^{2}\right)\end{array}$ & $\begin{array}{c}u_{\text {ccs }} \\
(\%)\end{array}$ & $\begin{array}{c}\mathrm{K}_{0} \\
\left(\mathrm{~cm}^{2} /\right. \\
\mathrm{V} \cdot \mathrm{s})\end{array}$ & $\begin{array}{l}U_{K 0} \\
(\%)\end{array}$ & $\begin{array}{c}\text { DT,1ry } \mathrm{CCS}_{\mathrm{N} 2} \\
\left(\AA^{2}\right)\end{array}$ & $\begin{array}{l}\text { Uccs } \\
(\%)\end{array}$ \\
\hline \multirow[t]{6}{*}{ transthyretin } & \multirow[t]{6}{*}{4} & \multirow[t]{6}{*}{56} & 10 & - & - & - & - & - & - & - & - & 0.546 & 1.5 & 3700 & 1.1 \\
\hline & & & 11 & - & - & - & - & - & - & - & - & 0.601 & 1.3 & 3700 & 0.8 \\
\hline & & & 12 & - & - & - & - & 0.649 & 1.3 & 3730 & 0.9 & 0.652 & 1.3 & 3710 & 0.8 \\
\hline & & & 13 & 0.704 & 1.3 & 3720 & 0.9 & 0.699 & 1.3 & 3750 & 0.9 & - & - & - & - \\
\hline & & & 14 & 0.752 & 1.3 & 3750 & 0.9 & 0.745 & 1.4 & 3790 & 1.0 & - & - & - & - \\
\hline & & & 15 & 0.796 & 1.3 & 3800 & 0.9 & - & - & - & - & - & - & - & - \\
\hline \multirow{6}{*}{$\begin{array}{l}\text { cholera } \\
\text { toxin B }\end{array}$} & \multirow[t]{6}{*}{5} & \multirow[t]{6}{*}{58} & 10 & - & - & - & - & - & - & - & - & 0.517 & 1.6 & 3910 & 1.3 \\
\hline & & & 11 & - & - & - & - & - & - & - & - & 0.567 & 1.5 & 3920 & 1.1 \\
\hline & & & 12 & - & - & - & - & - & - & - & - & 0.613 & 1.6 & 3950 & 1.2 \\
\hline & & & 13 & 0.667 & 1.4 & 3930 & 0.9 & 0.662 & 1.3 & 3960 & 0.8 & - & - & - & - \\
\hline & & & 14 & 0.709 & 1.3 & 3980 & 0.9 & 0.707 & 1.3 & 4000 & 0.8 & - & - & - & - \\
\hline & & & 15 & 0.749 & 1.3 & 4040 & 0.9 & 0.747 & 1.4 & 4060 & 0.9 & - & - & - & - \\
\hline \multirow[t]{5}{*}{ neutravidin } & \multirow[t]{5}{*}{4} & \multirow[t]{5}{*}{60} & 11 & - & - & - & - & - & - & - & - & 0.587 & 1.4 & 3790 & 0.9 \\
\hline & & & 12 & - & - & - & - & 0.619 & 1.4 & 3920 & 1.0 & 0.634 & 1.6 & 3830 & 1.2 \\
\hline & & & 13 & - & - & - & - & 0.664 & 1.3 & 3960 & 0.8 & - & - & - & - \\
\hline & & & 14 & 0.732 & 1.5 & 3870 & 1.1 & 0.711 & 1.3 & 3980 & 0.8 & - & - & - & - \\
\hline & & & 15 & 0.779 & 1.9 & 3890 & 1.6 & 0.757 & 1.3 & 4010 & 0.8 & - & - & - & - \\
\hline \multirow[t]{7}{*}{ avidin } & \multirow[t]{7}{*}{4} & \multirow[t]{7}{*}{64} & 11 & - & - & - & - & - & - & - & - & 0.565 & 1.3 & 3960 & 0.9 \\
\hline & & & 12 & - & - & - & - & - & - & - & - & 0.615 & 1.3 & 3960 & 0.8 \\
\hline & & & 13 & - & - & - & - & 0.662 & 1.4 & 3990 & 0.9 & 0.664 & 1.3 & 3980 & 0.9 \\
\hline & & & 14 & - & - & - & - & 0.709 & 1.4 & 4010 & 1.0 & - & - & - & - \\
\hline & & & 15 & 0.763 & 1.5 & 3990 & 1.1 & 0.758 & 1.4 & 4020 & 1.0 & - & - & - & - \\
\hline & & & 16 & 0.811 & 1.4 & 4010 & 1.0 & - & - & - & - & - & - & - & - \\
\hline & & & 17 & 0.855 & 1.4 & 4040 & 1.0 & - & - & - & - & - & - & - & - \\
\hline
\end{tabular}




\begin{tabular}{|c|c|c|c|c|c|c|c|c|c|c|c|c|c|c|c|}
\hline \multirow[b]{2}{*}{ Protein } & \multirow[b]{2}{*}{$\mathbf{n}$} & \multirow[b]{2}{*}{$\begin{array}{c}\text { MW } \\
\text { (kDa) }\end{array}$} & \multirow[b]{2}{*}{$\mathbf{z}$} & \multicolumn{4}{|c|}{ AmAc } & \multicolumn{4}{|c|}{ EDDA } & \multicolumn{4}{|c|}{ TEAA } \\
\hline & & & & $\begin{array}{c}\mathrm{K}_{0} \\
\left(\mathrm{~cm}^{2} /\right. \\
\mathrm{V} \cdot \mathrm{s})\end{array}$ & $\begin{array}{l}U_{K 0} \\
(\%)\end{array}$ & $\begin{array}{c}\text { DT,1ry } C \text { CCS } \\
\left(\AA_{\mathrm{N} 2}\right) \\
\left(\AA^{2}\right)\end{array}$ & $\begin{array}{l}u_{c c s} \\
(\%)\end{array}$ & $\begin{array}{c}\mathrm{K}_{0} \\
\left(\mathrm{~cm}^{2} /\right. \\
\mathrm{V} \cdot \mathrm{s})\end{array}$ & $\begin{array}{l}U_{K 0} \\
(\%)\end{array}$ & $\begin{array}{c}\text { DT,1ry } C \text { CCS } \\
\left(\AA_{\mathrm{N} 2}\right) \\
\left(\AA^{2}\right)\end{array}$ & $\begin{array}{l}U_{c c s} \\
(\%)\end{array}$ & $\begin{array}{c}\mathrm{K}_{0} \\
\left(\mathrm{~cm}^{2} /\right. \\
\mathrm{V} \cdot \mathrm{s})\end{array}$ & $\begin{array}{l}\mathrm{U}_{\mathrm{KO}} \\
(\%)\end{array}$ & $\begin{array}{c}\text { DT,1ry } C \text { CCS } \\
\left(\AA_{N 2}\right) \\
\left(\AA^{2}\right)\end{array}$ & $\begin{array}{l}U_{c c s} \\
(\%)\end{array}$ \\
\hline \multirow{7}{*}{$\begin{array}{l}\text { bovine } \\
\text { serum } \\
\text { albumin }\end{array}$} & \multirow[t]{7}{*}{1} & \multirow[t]{7}{*}{66} & 11 & - & - & - & - & - & - & - & - & 0.523 & 1.7 & 4240 & 1.2 \\
\hline & & & 12 & - & - & - & - & - & - & - & - & 0.569 & 1.7 & 4250 & 1.3 \\
\hline & & & 13 & - & - & - & - & 0.605 & 1.4 & 4330 & 1.3 & - & - & - & - \\
\hline & & & 14 & 0.646 & 1.3 & 4400 & 0.8 & 0.647 & 1.4 & 4370 & 1.2 & - & - & - & - \\
\hline & & & 15 & 0.685 & 1.3 & 4450 & 0.8 & 0.680 & 1.6 & 4450 & 1.3 & - & - & - & - \\
\hline & & & 16 & 0.721 & 1.3 & 4510 & 0.8 & - & - & - & - & - & - & - & - \\
\hline & & & 17 & 0.752 & 1.4 & 4590 & 1.0 & - & - & - & - & - & - & - & - \\
\hline \multirow{6}{*}{$\begin{array}{c}\text { concanavalin } \\
\text { A }\end{array}$} & \multirow[t]{6}{*}{4} & \multirow[t]{6}{*}{103} & 14 & - & - & - & - & - & - & - & - & 0.482 & 1.4 & 5840 & 0.9 \\
\hline & & & 15 & - & - & - & - & - & - & - & - & 0.516 & 1.3 & 5850 & 0.9 \\
\hline & & & 17 & - & - & - & - & 0.580 & 1.8 & 5940 & 1.3 & - & - & - & - \\
\hline & & & 18 & - & - & - & - & 0.615 & 1.6 & 5940 & 1.2 & - & - & - & - \\
\hline & & & 19 & 0.658 & 1.4 & 5850 & 1.0 & 0.645 & 1.7 & 5970 & 1.3 & - & - & - & - \\
\hline & & & 20 & 0.689 & 1.4 & 5880 & 0.9 & - & - & - & - & - & - & - & - \\
\hline \multirow{11}{*}{$\begin{array}{l}\text { C-reactive } \\
\text { protein }\end{array}$} & \multirow[t]{11}{*}{5} & \multirow[t]{11}{*}{115} & 16 & - & - & - & - & - & - & - & - & 0.469 & 1.4 & 6880 & 0.9 \\
\hline & & & 17 & - & - & - & - & - & - & - & - & 0.497 & 1.4 & 6900 & 1.0 \\
\hline & & & 18 & - & - & - & - & - & - & - & - & 0.524 & 1.4 & 6920 & 1.0 \\
\hline & & & 19 & - & - & - & - & 0.552 & 1.4 & 6930 & 1.0 & 0.550 & 1.3 & 6960 & 0.9 \\
\hline & & & 20 & - & - & - & - & 0.578 & 1.3 & 6980 & 0.9 & - & - & - & - \\
\hline & & & 21 & - & - & - & - & 0.604 & 1.3 & 7010 & 0.9 & - & - & - & - \\
\hline & & & 22 & - & - & - & - & 0.630 & 1.3 & 7030 & 0.8 & - & - & - & - \\
\hline & & & 23 & 0.652 & 1.6 & 7110 & 1.2 & 0.656 & 1.4 & 7070 & 0.9 & - & - & - & - \\
\hline & & & 24 & 0.677 & 1.4 & 7140 & 0.9 & - & - & - & - & - & - & - & - \\
\hline & & & 25 & 0.701 & 1.3 & 7180 & 0.9 & - & - & - & - & - & - & - & - \\
\hline & & & 26 & 0.721 & 1.4 & 7270 & 1.1 & - & - & - & - & - & - & - & - \\
\hline
\end{tabular}




\begin{tabular}{|c|c|c|c|c|c|c|c|c|c|c|c|c|c|c|c|}
\hline \multirow[b]{2}{*}{ Protein } & \multirow[b]{2}{*}{$\mathbf{n}$} & \multirow[b]{2}{*}{$\begin{array}{c}\text { MW } \\
\text { (kDa) }\end{array}$} & \multirow[b]{2}{*}{$\mathbf{z}$} & \multicolumn{4}{|c|}{ AmAc } & \multicolumn{4}{|c|}{ EDDA } & \multicolumn{4}{|c|}{ TEAA } \\
\hline & & & & $\begin{array}{c}\mathrm{K}_{0} \\
\left(\mathrm{~cm}^{2} /\right. \\
\mathrm{V} \cdot \mathrm{s})\end{array}$ & $\begin{array}{l}\mathrm{U}_{\mathrm{K} 0} \\
(\%)\end{array}$ & $\begin{array}{c}\text { DT,1ry } C_{C S} S_{\mathrm{N} 2} \\
\left(\AA^{2}\right)\end{array}$ & $\begin{array}{l}\mathbf{u}_{\mathrm{ccs}} \\
(\%)\end{array}$ & $\begin{array}{c}\mathrm{K}_{0} \\
\left(\mathrm{~cm}^{2} /\right. \\
\mathrm{V} \cdot \mathrm{s})\end{array}$ & $\begin{array}{l}U_{K 0} \\
(\%)\end{array}$ & $\begin{array}{c}\text { DT,1ry } \mathrm{CCS}_{\mathrm{N} 2} \\
\left(\AA^{2}\right)\end{array}$ & $\begin{array}{l}\text { Uccs } \\
(\%)\end{array}$ & $\begin{array}{c}\mathrm{K}_{0} \\
\left(\mathrm{~cm}^{2} /\right. \\
\mathrm{V} \cdot \mathrm{s})\end{array}$ & $\begin{array}{l}U_{K 0} \\
(\%)\end{array}$ & $\begin{array}{c}\text { DT,1ry } \mathrm{CCS}_{\mathrm{N} 2} \\
\left(\AA^{2}\right)\end{array}$ & $\begin{array}{l}\text { Uccs } \\
(\%)\end{array}$ \\
\hline \multirow{8}{*}{$\begin{array}{c}\text { alcohol } \\
\text { dehydrogenase }\end{array}$} & \multirow[t]{8}{*}{4} & \multirow[t]{8}{*}{147} & 17 & - & - & - & - & - & - & - & - & 0.467 & 1.4 & 7330 & 1.0 \\
\hline & & & 18 & - & - & - & - & - & - & - & - & 0.494 & 1.3 & 7330 & 0.9 \\
\hline & & & 19 & - & - & - & - & - & - & - & - & 0.521 & 1.3 & 7350 & 0.9 \\
\hline & & & 21 & - & - & - & - & 0.565 & 1.7 & 7540 & 1.3 & - & - & - & - \\
\hline & & & 22 & - & - & - & - & 0.598 & 1.5 & 7470 & 1.2 & - & - & - & - \\
\hline & & & 23 & 0.620 & 1.4 & 7510 & 0.9 & 0.620 & 1.6 & 7530 & 1.2 & - & - & - & - \\
\hline & & & 24 & 0.644 & 1.4 & 7540 & 0.8 & - & - & - & - & - & - & - & - \\
\hline & & & 25 & 0.669 & 1.4 & 7570 & 0.8 & - & - & - & - & - & - & - & - \\
\hline \multirow{11}{*}{$\begin{array}{c}\text { phosphorylase } \\
\text { B }\end{array}$} & \multirow[t]{11}{*}{2} & \multirow[t]{11}{*}{195} & 19 & - & - & - & - & - & - & - & - & 0.420 & 1.6 & 9120 & 1.2 \\
\hline & & & 20 & - & - & - & - & - & - & - & - & 0.441 & 1.4 & 9140 & 0.9 \\
\hline & & & 21 & - & - & - & - & - & - & - & - & 0.463 & 1.4 & 9140 & 0.9 \\
\hline & & & 22 & - & - & - & - & - & - & - & - & 0.485 & 1.5 & 9140 & 1.0 \\
\hline & & & 23 & - & - & - & - & 0.501 & 1.6 & 9240 & 1.2 & - & - & - & - \\
\hline & & & 24 & - & - & - & - & 0.522 & 1.6 & 9260 & 1.2 & - & - & - & - \\
\hline & & & 25 & - & - & - & - & 0.542 & 1.6 & 9290 & 1.2 & - & - & - & - \\
\hline & & & 26 & 0.568 & 1.5 & 9230 & 1.1 & 0.562 & 1.5 & 9320 & 1.1 & - & - & - & - \\
\hline & & & 27 & 0.589 & 1.5 & 9250 & 1.1 & 0.580 & 1.4 & 9380 & 1.0 & - & - & - & - \\
\hline & & & 28 & 0.609 & 1.5 & 9270 & 1.1 & - & - & - & - & - & - & - & - \\
\hline & & & 29 & 0.627 & 1.5 & 9330 & 1.0 & - & - & - & - & - & - & - & - \\
\hline \multirow{11}{*}{$\begin{array}{c}\text { pyruvate } \\
\text { kinase }\end{array}$} & \multirow[t]{11}{*}{4} & \multirow[t]{11}{*}{237} & 23 & - & - & - & - & - & - & - & - & 0.450 & 1.5 & 10280 & 1.1 \\
\hline & & & 24 & - & - & - & - & - & - & - & - & 0.467 & 1.5 & 10340 & 1.0 \\
\hline & & & 25 & - & - & - & - & - & - & - & - & 0.485 & 1.5 & 10370 & 1.1 \\
\hline & & & 26 & - & - & - & - & - & - & - & - & 0.504 & 1.4 & 10380 & 1.0 \\
\hline & & & 28 & - & - & - & - & 0.532 & 1.5 & 10600 & 1.1 & - & - & - & - \\
\hline & & & 29 & - & - & - & - & 0.548 & 1.4 & 10670 & 1.1 & - & - & - & - \\
\hline & & & 30 & - & - & - & - & 0.565 & 1.5 & 10700 & 1.2 & - & - & - & - \\
\hline & & & 31 & 0.591 & 1.4 & 10580 & 0.9 & 0.582 & 1.5 & 10730 & 1.3 & - & - & - & - \\
\hline & & & 32 & 0.609 & 1.4 & 10610 & 0.9 & - & - & - & - & - & - & - & - \\
\hline & & & 33 & 0.628 & 1.4 & 10610 & 0.9 & - & - & - & - & - & - & - & - \\
\hline & & & 34 & 0.648 & 1.4 & 10600 & 0.9 & - & - & - & - & - & - & - & - \\
\hline
\end{tabular}




\begin{tabular}{|c|c|c|c|c|c|c|c|c|c|c|c|c|c|c|c|}
\hline \multirow[b]{2}{*}{ Protein } & \multirow[b]{2}{*}{$\mathbf{n}$} & \multirow[b]{2}{*}{$\begin{array}{c}\text { MW } \\
\text { (kDa) }\end{array}$} & \multirow[b]{2}{*}{$\mathbf{z}$} & \multicolumn{4}{|c|}{ AmAc } & \multicolumn{4}{|c|}{ EDDA } & \multicolumn{4}{|c|}{ TEAA } \\
\hline & & & & $\begin{array}{c}\mathrm{K}_{0} \\
\left(\mathrm{~cm}^{2} /\right. \\
\mathrm{V} \cdot \mathrm{s})\end{array}$ & $\begin{array}{l}\mathrm{U}_{\mathrm{K} 0} \\
(\%)\end{array}$ & $\begin{array}{c}\text { DT,1ry } \text { CCS }_{\mathrm{N} 2} \\
\left(\AA^{2}\right)\end{array}$ & $\begin{array}{l}\mathbf{u}_{\mathrm{ccs}} \\
(\%)\end{array}$ & $\begin{array}{c}\mathrm{K}_{0} \\
\left(\mathrm{~cm}^{2} /\right. \\
\mathrm{V} \cdot \mathrm{s}) \\
\end{array}$ & $\begin{array}{l}U_{K 0} \\
(\%)\end{array}$ & $\begin{array}{c}\text { DT,1ry } \text { CCS }_{\mathrm{N} 2} \\
\left(\AA^{2}\right)\end{array}$ & $\begin{array}{l}\text { Uccs }_{\text {ccs }} \\
(\%)\end{array}$ & $\begin{array}{c}\mathrm{K}_{0} \\
\left(\mathrm{~cm}^{2} /\right. \\
\mathrm{V} \cdot \mathrm{s})\end{array}$ & $\begin{array}{l}\mathrm{UK}_{\mathrm{K} 0} \\
(\%)\end{array}$ & $\begin{array}{c}\text { DT,1ry } C_{C S} C_{\mathrm{N} 2} \\
\left(\AA^{2}\right)\end{array}$ & $\begin{array}{l}\text { Uccs } \\
(\%)\end{array}$ \\
\hline \multirow{14}{*}{$\begin{array}{c}\text { glutamate } \\
\text { dehydrogenase }\end{array}$} & \multirow[t]{14}{*}{6} & \multirow[t]{14}{*}{336} & 25 & - & - & - & - & - & - & - & - & 0.404 & 1.6 & 12450 & 1.3 \\
\hline & & & 26 & - & - & - & - & - & - & - & - & 0.421 & 1.5 & 12440 & 1.1 \\
\hline & & & 27 & - & - & - & - & - & - & - & - & 0.437 & 1.4 & 12430 & 0.9 \\
\hline & & & 28 & - & - & - & - & - & - & - & - & 0.453 & 1.4 & 12430 & 0.9 \\
\hline & & & 29 & - & - & - & - & - & - & - & - & 0.469 & 1.4 & 12440 & 0.9 \\
\hline & & & 30 & - & - & - & - & 0.476 & 1.3 & 12700 & 0.9 & - & - & - & - \\
\hline & & & 31 & - & - & - & - & 0.491 & 1.3 & 12720 & 0.8 & - & - & - & - \\
\hline & & & 32 & - & - & - & - & 0.507 & 1.3 & 12710 & 0.8 & - & - & - & - \\
\hline & & & 33 & - & - & - & - & 0.523 & 1.3 & 12720 & 0.8 & - & - & - & - \\
\hline & & & 34 & - & - & - & - & 0.537 & 1.3 & 12760 & 0.8 & - & - & - & - \\
\hline & & & 35 & 0.553 & 1.7 & 12770 & 1.3 & - & - & - & - & - & - & - & - \\
\hline & & & 36 & 0.568 & 1.3 & 12790 & 0.8 & - & - & - & - & - & - & - & - \\
\hline & & & 37 & 0.581 & 1.3 & 12850 & 0.8 & - & - & - & - & - & - & - & - \\
\hline & & & 38 & 0.595 & 1.3 & 12890 & 0.8 & - & - & - & - & - & - & - & - \\
\hline \multirow{12}{*}{$\begin{array}{c}\text { Beta- } \\
\text { galactosidase }\end{array}$} & \multirow[t]{12}{*}{4} & \multirow[t]{12}{*}{466} & 31 & - & - & - & - & - & - & - & - & 0.424 & 1.6 & 14790 & 1.2 \\
\hline & & & 32 & - & - & - & - & - & - & - & - & 0.413 & 1.6 & 15680 & 1.2 \\
\hline & & & 33 & - & - & - & - & - & - & - & - & 0.422 & 1.4 & 15820 & 0.9 \\
\hline & & & 34 & - & - & - & - & - & - & - & - & 0.434 & 1.4 & 15860 & 0.9 \\
\hline & & & 35 & - & - & - & - & - & - & - & - & 0.447 & 1.4 & 15840 & 0.9 \\
\hline & & & 36 & - & - & - & - & - & - & - & - & 0.461 & 1.4 & 15810 & 0.9 \\
\hline & & & 37 & - & - & - & - & - & - & - & - & 0.472 & 1.5 & 15840 & 1.1 \\
\hline & & & 44 & 0.553 & 1.6 & 16060 & 1.0 & - & - & - & - & - & - & - & - \\
\hline & & & 45 & 0.564 & 1.4 & 16120 & 0.9 & - & - & - & - & - & - & - & - \\
\hline & & & 46 & 0.575 & 1.4 & 16150 & 0.9 & - & - & - & - & - & - & - & - \\
\hline & & & 47 & 0.589 & 1.4 & 16120 & 0.9 & - & - & - & - & - & - & - & - \\
\hline & & & 48 & 0.602 & 1.4 & 16110 & 0.9 & - & - & - & - & - & - & - & - \\
\hline
\end{tabular}




\begin{tabular}{|c|c|c|c|c|c|c|c|c|c|c|c|c|c|c|c|}
\hline \multirow[b]{2}{*}{ Protein } & \multirow[b]{2}{*}{$\mathbf{n}$} & \multirow[b]{2}{*}{$\begin{array}{c}\text { MW } \\
\text { (kDa) }\end{array}$} & \multirow[b]{2}{*}{$\mathbf{z}$} & \multicolumn{4}{|c|}{ AmAc } & \multicolumn{4}{|c|}{ EDDA } & \multicolumn{4}{|c|}{ TEAA } \\
\hline & & & & $\begin{array}{c}\mathrm{K}_{0} \\
\left(\mathrm{~cm}^{2} /\right. \\
\mathrm{V} \cdot \mathrm{s})\end{array}$ & $\begin{array}{l}\mathrm{U}_{\mathrm{K} 0} \\
(\%)\end{array}$ & $\begin{array}{c}\mathrm{DT}, 1 \mathrm{ry} C \mathrm{C} \mathrm{S}_{\mathrm{N} 2} \\
\left(\AA^{2}\right)\end{array}$ & $\begin{array}{c}\text { U ucs }_{\text {ccs }} \\
(\%)\end{array}$ & $\begin{array}{c}\mathrm{K}_{0} \\
\left(\mathrm{~cm}^{2} /\right. \\
\mathrm{V} \cdot \mathbf{s})\end{array}$ & $\begin{array}{l}U_{K 0} \\
(\%)\end{array}$ & $\begin{array}{c}{ }^{\mathrm{DT}, 1 \mathrm{ry} y} \mathrm{CCS} \mathrm{S}_{\mathrm{N} 2} \\
\left(\AA^{2}\right)\end{array}$ & $\begin{array}{l}\text { Uccs } \\
(\%)\end{array}$ & $\begin{array}{c}\mathrm{K}_{0} \\
\left(\mathrm{~cm}^{2} /\right. \\
\mathrm{V} \cdot \mathrm{s})\end{array}$ & $\begin{array}{l}\mathrm{U}_{\mathrm{K} 0} \\
(\%)\end{array}$ & $\begin{array}{c}\text { DT,1ry } C \text { CCS } S_{\mathrm{N} 2} \\
\left(\AA^{2}\right)\end{array}$ & $\begin{array}{l}U_{\text {ccs }} \\
(\%)\end{array}$ \\
\hline \multirow{16}{*}{$\begin{array}{l}\text { glutamine } \\
\text { synthetase }\end{array}$} & \multirow[t]{16}{*}{12} & \multirow[t]{16}{*}{620.2} & 34 & - & - & - & - & - & - & - & - & 0.383 & 1.3 & 17990 & 0.9 \\
\hline & & & 35 & - & - & - & - & - & - & - & - & 0.393 & 1.3 & 18040 & 0.8 \\
\hline & & & 36 & - & - & - & - & - & - & - & - & 0.405 & 1.4 & 18020 & 0.9 \\
\hline & & & 37 & - & - & - & - & - & - & - & - & 0.416 & 1.4 & 18000 & 1.0 \\
\hline & & & 38 & - & - & - & - & - & - & - & - & 0.428 & 1.4 & 17980 & 0.9 \\
\hline & & & 39 & - & - & - & - & 0.448 & 1.8 & 17650 & 1.5 & 0.437 & 1.6 & 18090 & 1.2 \\
\hline & & & 40 & - & - & - & - & 0.457 & 1.4 & 17750 & 0.9 & - & - & - & - \\
\hline & & & 41 & - & - & - & - & 0.468 & 1.3 & 17760 & 0.8 & - & - & - & - \\
\hline & & & 42 & - & - & - & - & 0.480 & 1.3 & 17740 & 0.8 & - & - & - & - \\
\hline & & & 43 & - & - & - & - & 0.491 & 1.3 & 17720 & 0.8 & - & - & - & - \\
\hline & & & 44 & - & - & - & - & 0.495 & 1.5 & 18020 & 1.1 & - & - & - & - \\
\hline & & & 50 & 0.563 & 1.4 & 17980 & 1.0 & - & - & - & - & - & - & - & - \\
\hline & & & 51 & 0.572 & 1.3 & 18040 & 0.8 & - & - & - & - & - & - & - & - \\
\hline & & & 52 & 0.582 & 1.3 & 18090 & 0.8 & - & - & - & - & - & - & - & - \\
\hline & & & 53 & 0.593 & 1.3 & 18110 & 0.8 & - & - & - & - & - & - & - & - \\
\hline & & & 54 & 0.604 & 1.3 & 18100 & 0.8 & - & - & - & - & - & - & - & - \\
\hline \multirow[t]{5}{*}{ GroEL } & \multirow[t]{5}{*}{12} & \multirow[t]{5}{*}{801} & 45 & - & - & - & - & - & - & - & - & 0.446 & 1.7 & 20400 & 1.4 \\
\hline & & & 46 & - & - & - & - & - & - & - & - & 0.453 & 1.6 & 20540 & 1.2 \\
\hline & & & 47 & - & - & - & - & - & - & - & - & 0.464 & 1.6 & 20520 & 1.2 \\
\hline & & & 48 & - & - & - & - & - & - & - & - & 0.474 & 1.6 & 20480 & 1.2 \\
\hline & & & 49 & - & - & - & - & - & - & - & - & 0.486 & 1.6 & 20420 & 1.3 \\
\hline
\end{tabular}


Table S9. Experimentally observed molecular weights for each protein in helium drift gas. Error is shown as standard deviation of triplicate measurements for each individual charge state.

\begin{tabular}{|c|c|c|c|c|c|c|c|}
\hline \multirow[b]{2}{*}{ Protein } & \multirow[b]{2}{*}{ Charge } & \multicolumn{3}{|c|}{ He drift gas } & \multicolumn{3}{|c|}{$\mathrm{N}_{2}$ drift gas } \\
\hline & & $\begin{array}{c}\text { MW (Da), } \\
\text { AmAc }\end{array}$ & $\begin{array}{l}\text { MW (Da), } \\
\text { EDDA }\end{array}$ & $\begin{array}{c}\text { MW (Da), } \\
\text { TEAA }\end{array}$ & $\begin{array}{c}\text { MW (Da), } \\
\text { AmAc }\end{array}$ & $\begin{array}{c}\text { MW (Da), } \\
\text { EDDA }\end{array}$ & $\begin{array}{c}\text { MW (Da), } \\
\text { TEAA }\end{array}$ \\
\hline \multirow[t]{4}{*}{ UB } & 3 & & $8565+/-0.1$ & $8564+/-0.5$ & & & \\
\hline & 4 & $8564+/-1$ & $8565+/-0.7$ & $8564+/-0.3$ & $8564+/-0.7$ & $8565+/-0.1$ & $8565+/-0.04$ \\
\hline & 5 & $8564+/-0$ & $8565+/-0.7$ & & $8564+/-0.8$ & $8565+/-0.1$ & $8565+/-0.4$ \\
\hline & 6 & & & & $8564+/-0.9$ & & $8565+/-0.6$ \\
\hline \multirow[t]{4}{*}{ BLGA1 } & 6 & & & $18364+/-0.4$ & & & \\
\hline & 7 & & $18418+/-92$ & $18387+/-1$ & & $18365+/-0.4$ & $18365+/-0.8$ \\
\hline & 8 & $18368+/-1$ & $18315+/-86$ & & $18365+/-0.8$ & & \\
\hline & 9 & $18371+/-1$ & & & & & \\
\hline \multirow[t]{7}{*}{$\overline{\mathrm{CA}}$} & 5 & & & & & & $29125+/-5$ \\
\hline & 6 & & & $29160+/-19$ & & & $29087+/-0.3$ \\
\hline & 7 & & $29149+/-2$ & $29160+/-17$ & & $29087+/-0.3$ & $29101+/-0.3$ \\
\hline & 8 & $29162+/-24$ & $29149+/-0.4$ & $29166+/-23$ & $29087+/-0.2$ & $29087+/-0.5$ & $29087+/-0.3$ \\
\hline & 9 & $29152+/-5$ & $29149+/-0.1$ & & $29087+/-0.2$ & $29087+/-0.6$ & \\
\hline & 10 & $29151+/-3$ & $29149+/-0.3$ & & $29087+/-0.1$ & $29087+/-0.4$ & \\
\hline & 11 & $29152+/-5$ & & & & & \\
\hline \multirow[t]{6}{*}{ BLGA2 } & 8 & & & $36740+/-3$ & & & $36860+/-191$ \\
\hline & 9 & & & $36740+/-3$ & & & $36745+/-12$ \\
\hline & 10 & & $36788+/-94$ & & & $36741+/-17$ & \\
\hline & 11 & $36766+/-35$ & $36810+/-131$ & & $36730+/-2$ & $36750+/-32$ & \\
\hline & 12 & $36761+/-30$ & & & & & \\
\hline & 13 & $36767+/-33$ & & & & & \\
\hline \multirow[t]{7}{*}{$\overline{S A}$} & 9 & & & $53563+/-114$ & & & \\
\hline & 10 & & & $53491+/-107$ & & & $53609+/-197$ \\
\hline & 11 & & $53730+/-79$ & $53518+/-142$ & & & $53520+/-88$ \\
\hline & 12 & & $53735+/-136$ & & & $53446+/-114$ & $53373+/-79$ \\
\hline & 13 & $53473+/-164$ & $53799+/-95$ & & $53422+/-62$ & $53399+/-53$ & \\
\hline & 14 & $53443+/-121$ & $53899+/-11$ & & $53393+/-26$ & $53446+/-34$ & \\
\hline & 15 & $53447+/-121$ & & & $53391+/-22$ & & \\
\hline \multirow[t]{6}{*}{$\overline{T T R}$} & 10 & & & $55925+/-75$ & & & $55907+/-33$ \\
\hline & 11 & & & $56022+/-143$ & & & $55972+/-40$ \\
\hline & 12 & & $56188+/-217$ & $56092+/-199$ & & $56076+/-245$ & $56076+/-216$ \\
\hline & 13 & $55889+/-223$ & $56410+/-244$ & & $55880+/-404$ & $56099+/-197$ & \\
\hline & 14 & $55899+/-171$ & $56346+/-325$ & & $55786+/-247$ & $55953+/-179$ & \\
\hline & 15 & $55906+/-210$ & & & $55831+/-133$ & & \\
\hline \multirow{6}{*}{ CTB } & 10 & & & $59128+/-465$ & & & $58495+/-74$ \\
\hline & 11 & & & $59500+/-813$ & & & $58343+/-141$ \\
\hline & 12 & & & $59727+/-1086$ & & & $58615+/-324$ \\
\hline & 13 & & $58777+/-413$ & & $58261+/-36$ & $58533+/-202$ & \\
\hline & 14 & $58888+/-419$ & $59219+/-506$ & & $58245+/-48$ & $58473+/-82$ & \\
\hline & 15 & $58706+/-354$ & $59330+/-564$ & & $58153+/-40$ & $58381+/-116$ & \\
\hline \multirow[t]{6}{*}{ NAV } & 11 & & & $60230+/-85$ & & & $60327+/-120$ \\
\hline & 12 & & & $60299+/-46$ & & $60509+/-234$ & $60350+/-165$ \\
\hline & 13 & & $60556+/-107$ & & & $60410+/-79$ & \\
\hline & 14 & $60258+/-73$ & $60573+/-158$ & & $60067+/-10$ & $60327+/-111$ & \\
\hline & 15 & $60059+/-111$ & $60507+/-194$ & & $60085+/-42$ & $60304+/-114$ & \\
\hline & 16 & $60135+/-97$ & & & & & \\
\hline \multirow[t]{8}{*}{$\overline{A V}$} & 10 & & & $64279+/-78$ & & & \\
\hline & 11 & & & $64255+/-192$ & & & $64219+/-312$ \\
\hline & 12 & & & $64293+/-172$ & & & $64189+/-246$ \\
\hline & 13 & & $64602+/-775$ & $64437+/-187$ & & $64170+/-292$ & $64346+/-266$ \\
\hline & 14 & $63881+/-28$ & $64464+/-494$ & & & $64150+/-285$ & \\
\hline & 15 & $63863+/-92$ & $64565+/-377$ & & $63924+/-128$ & $64065+/-439$ & \\
\hline & 16 & $63884+/-15$ & $64819+/-507$ & & $36938+/-151$ & & \\
\hline & 17 & $63952+/-184$ & & & $64001+/-67$ & & \\
\hline \multirow[t]{4}{*}{$\overline{B S A}$} & 10 & & & $67330+/-282$ & & & \\
\hline & 11 & & & $67255+/-268$ & & & $66918+/-220$ \\
\hline & 12 & & & $67258+/-267$ & & & $66908+/-250$ \\
\hline & 13 & & $67892+/-623$ & $67303+/-160$ & & $67038+/-241$ & \\
\hline
\end{tabular}




\begin{tabular}{|c|c|c|c|c|c|c|c|}
\hline \multirow{2}{*}{ Protein } & \multirow[b]{2}{*}{ Charge } & \multicolumn{3}{|c|}{ He drift gas } & \multicolumn{3}{|c|}{$\mathbf{N}_{2}$ drift gas } \\
\hline & & $\begin{array}{c}\text { MW (Da), } \\
\text { AmAc }\end{array}$ & $\begin{array}{c}\text { MW (Da), } \\
\text { EDDA }\end{array}$ & $\begin{array}{c}\text { MW (Da), } \\
\text { TEAA }\end{array}$ & $\begin{array}{c}\text { MW (Da), } \\
\text { AmAc }\end{array}$ & $\begin{array}{c}\text { MW (Da), } \\
\text { EDDA }\end{array}$ & $\begin{array}{c}\text { MW (Da), } \\
\text { TEAA }\end{array}$ \\
\hline \multirow[t]{4}{*}{ BSA (cont.) } & 14 & $67091+/-272$ & $67854+/-514$ & & $67011+/-211$ & $67015+/-123$ & \\
\hline & 15 & $67104+/-304$ & $67985+/-507$ & & $66980+/-229$ & $67115+/-195$ & \\
\hline & 16 & $67185+/-258$ & & & $66893+/-129$ & & \\
\hline & 17 & $67357+/-215$ & & & $66649+/-107$ & & \\
\hline \multirow[t]{8}{*}{ ConA } & 13 & & & $103087+/-132$ & & & \\
\hline & 14 & & & $103102+/-95$ & & & $103089+/-251$ \\
\hline & 15 & & & $103030+/-77$ & & & $103023+/-188$ \\
\hline & 16 & & $104352+/-315$ & & & & \\
\hline & 17 & & $104424+/-296$ & & & $103566+/-354$ & \\
\hline & 18 & $102767+/-199$ & $104412+/-434$ & & & $103128+/-161$ & \\
\hline & 19 & $102767+/-142$ & & & $102770+/-176$ & $103438+/-239$ & \\
\hline & 20 & $102732+/-86$ & & & $102729+/-98$ & & \\
\hline \multirow[t]{11}{*}{ CRP } & 16 & & & $116630+/-84$ & & & $115575+/-386$ \\
\hline & 17 & & & $116475+/-81$ & & & $115669+/-339$ \\
\hline & 18 & & & 116626 +/- 218 & & & $115628+/-324$ \\
\hline & 19 & & $115776+/-404$ & $116319+/-314$ & & $115522+/-58$ & $115750+/-422$ \\
\hline & 20 & & $115765+/-157$ & & & $115535+/-162$ & \\
\hline & 21 & & $115821+/-302$ & & & $115423+/-61$ & \\
\hline & 22 & & $115763+/-386$ & & & $115393+/-86$ & \\
\hline & 23 & $115792+/-504$ & $115841+/-428$ & & $115271+/-83$ & $115375+/-123$ & \\
\hline & 24 & $115750+/-544$ & & & $115319+/-156$ & & \\
\hline & 25 & $115829+/-362$ & & & $115312+/-151$ & & \\
\hline & 26 & $115806+/-414$ & & & $115333+/-170$ & & \\
\hline \multirow[t]{9}{*}{$\overline{\mathrm{ADH}}$} & 17 & & & $148920+/-156$ & & & $148751+/-117$ \\
\hline & 18 & & & $148936+/-207$ & & & $148886+/-92$ \\
\hline & 19 & & & $148937+/-248$ & & & $148965+/-491$ \\
\hline & 20 & & $150328+/-146$ & & & & \\
\hline & 21 & & $150496+/-880$ & & & $150252+/-284$ & \\
\hline & 22 & & $150682+/-675$ & & & $150330+/-307$ & \\
\hline & 23 & $149323+/-721$ & $150868+/-694$ & & $148493+/-432$ & $150745+/-274$ & \\
\hline & 24 & $149431+/-757$ & & & $148706+/-555$ & & \\
\hline & 25 & $149336+/-742$ & & & $148681+/-541$ & & \\
\hline \multirow[t]{12}{*}{$\overline{\mathrm{PHB}}$} & 19 & & & & & & $197836+/-965$ \\
\hline & 20 & & & $197213+/-751$ & & & $197049+/-395$ \\
\hline & 21 & & & 197444 +/- 904 & & & $197069+/-481$ \\
\hline & 22 & & & $197710+/-1101$ & & & $197217+/-887$ \\
\hline & 23 & & $197504+/-191$ & & & $197610+/-784$ & \\
\hline & 24 & & $197637+/-445$ & & & $197425+/-463$ & \\
\hline & 25 & & $197653+/-344$ & & & $197386+/-475$ & \\
\hline & 26 & $196558+/-610$ & $197467+/-667$ & & $196290+/-207$ & $197546+/-797$ & \\
\hline & 27 & $196532+/-539$ & $197664+/-183$ & & $196546+/-451$ & $197510+/-399$ & \\
\hline & 28 & $196535+/-619$ & & & $196386+/-406$ & & \\
\hline & 29 & $196600+/-687$ & & & $196537+/-586$ & & \\
\hline & 30 & $196552+/-602$ & & & & & \\
\hline \multirow[t]{11}{*}{$\mathrm{PK}$} & 23 & & & $234644+/-504$ & & & $233971+/-142$ \\
\hline & 24 & & & $234355+/-482$ & & & $234108+/-363$ \\
\hline & 25 & & & $234289+/-370$ & & & $234069+/-466$ \\
\hline & 26 & & & & & & $233834+/-265$ \\
\hline & 28 & & & & & $235423+/-442$ & \\
\hline & 29 & & $236456+/-522$ & & & $235643+/-423$ & \\
\hline & 30 & & $236503+/-389$ & & & $235307+/-213$ & \\
\hline & 31 & $233772+/-194$ & $236483+/-169$ & & $233755+/-285$ & $235373+/-157$ & \\
\hline & 32 & $233693+/-268$ & & & $233635+/-257$ & & \\
\hline & 33 & $233651+/-227$ & & & $233534+/-228$ & & \\
\hline & 34 & $233526+/-210$ & & & $233419+/-125$ & & \\
\hline \multirow[t]{7}{*}{$\overline{\mathrm{GDH}}$} & 25 & & & & & & $340267+/-1103$ \\
\hline & 26 & & & $339829+/-302$ & & & $340158+/-1239$ \\
\hline & 27 & & & $339411+/-193$ & & & $339656+/-1138$ \\
\hline & 28 & & & $338949+/-794$ & & & $339632+/-894$ \\
\hline & 29 & & & & & & $339551+/-1005$ \\
\hline & 30 & & & & & $342089+/-591$ & \\
\hline & 31 & & $144861+/-1676$ & & & $342481+/-264$ & \\
\hline
\end{tabular}




\begin{tabular}{|c|c|c|c|c|c|c|c|}
\hline \multirow{2}{*}{ Protein } & \multirow[b]{2}{*}{ Charge } & \multicolumn{3}{|c|}{ He drift gas } & \multicolumn{3}{|c|}{$\mathrm{N}_{2}$ drift gas } \\
\hline & & $\begin{array}{c}\text { MW (Da), } \\
\text { AmAc }\end{array}$ & $\begin{array}{c}\text { MW (Da), } \\
\text { EDDA }\end{array}$ & $\begin{array}{c}\text { MW (Da), } \\
\text { TEAA }\end{array}$ & $\begin{array}{c}\text { MW (Da), } \\
\text { AmAc }\end{array}$ & $\begin{array}{c}\text { MW (Da), } \\
\text { EDDA }\end{array}$ & $\begin{array}{c}\text { MW (Da), } \\
\text { TEAA }\end{array}$ \\
\hline \multirow[t]{7}{*}{ GDH (cont.) } & 32 & & $345074+/-1861$ & & & $342384+/-365$ & \\
\hline & 33 & & $345770+/-1442$ & & & $342761+/-348$ & \\
\hline & 34 & & & & & $342365+/-575$ & \\
\hline & 35 & $338870+/-1018$ & & & $337916+/-295$ & & \\
\hline & 36 & $339104+/-674$ & & & $338111+/-771$ & & \\
\hline & 37 & $339089+/-1037$ & & & $337866+/-747$ & & \\
\hline & 38 & $338926+/-1049$ & & & $337863+/-754$ & & \\
\hline \multirow[t]{12}{*}{ B-gal } & 31 & & & & & & $467556+/-613$ \\
\hline & 32 & & & $470646+/-1107$ & & & $470821+/-100$ \\
\hline & 33 & & & $470511+/-1330$ & & & $470703+/-736$ \\
\hline & 34 & & & $470324+/-1044$ & & & $470454+/-445$ \\
\hline & 35 & & & $470175+/-1072$ & & & $470371+/-369$ \\
\hline & 36 & & & & & & $470083+/-411$ \\
\hline & 37 & & & & & & $469944+/-117$ \\
\hline & 44 & $468157+/-1109$ & & & $467721+/-457$ & & \\
\hline & 45 & $468088+/-1057$ & & & $468091+/-788$ & & \\
\hline & 46 & $467927+/-1025$ & & & $467942+/-800$ & & \\
\hline & 47 & $467798+/-930$ & & & $467786+/-770$ & & \\
\hline & 48 & $467692+/-831$ & & & $467728+/-848$ & & \\
\hline \multirow[t]{17}{*}{ GS } & 34 & & & $631763+/-443$ & & & $632140+/-370$ \\
\hline & 35 & & & $632314+/-785$ & & & $632864+/-224$ \\
\hline & 36 & & & $632429+/-826$ & & & $633453+/-211$ \\
\hline & 37 & & & $632809+/-1104$ & & & $633873+/-462$ \\
\hline & 38 & & & $634047+/-925$ & & & $634399+/-665$ \\
\hline & 39 & & $624848+/-551$ & & & $623799+/-428$ & $634456+/-497$ \\
\hline & 40 & & $625450+/-350$ & & & $625108+/-263$ & \\
\hline & 41 & & $625495+/-166$ & & & $624690+/-511$ & \\
\hline & 42 & & $625867+/-357$ & & & $625149+/-380$ & \\
\hline & 43 & & $625933+/-453$ & & & $625782+/-337$ & \\
\hline & 44 & & $624342+/-660$ & & & $624138+/-696$ & \\
\hline & 50 & $628464+/-668$ & & & $628052+/-1283$ & & \\
\hline & 51 & $628255+/-222$ & & & $627923+/-1058$ & & \\
\hline & 52 & $628490+/-476$ & & & $628028+/-1133$ & & \\
\hline & 53 & $628500+/-295$ & & & $628093+/-888$ & & \\
\hline & 54 & $628287+/-144$ & & & $628115+/-678$ & & \\
\hline & 55 & $628485+/-204$ & & & & & \\
\hline \multirow[t]{6}{*}{ GroEL } & 45 & & & $813656+/-1043$ & & & $812888+/-402$ \\
\hline & 46 & & & $812887+/-916$ & & & $812862+/-586$ \\
\hline & 47 & & & $812932+/-728$ & & & $812786+/-456$ \\
\hline & 48 & & & $813635+/-115$ & & & $813235+/-526$ \\
\hline & 49 & & & $813645+/-671$ & & & $813136+/-250$ \\
\hline & 50 & & & $813388+/-1194$ & & & \\
\hline
\end{tabular}



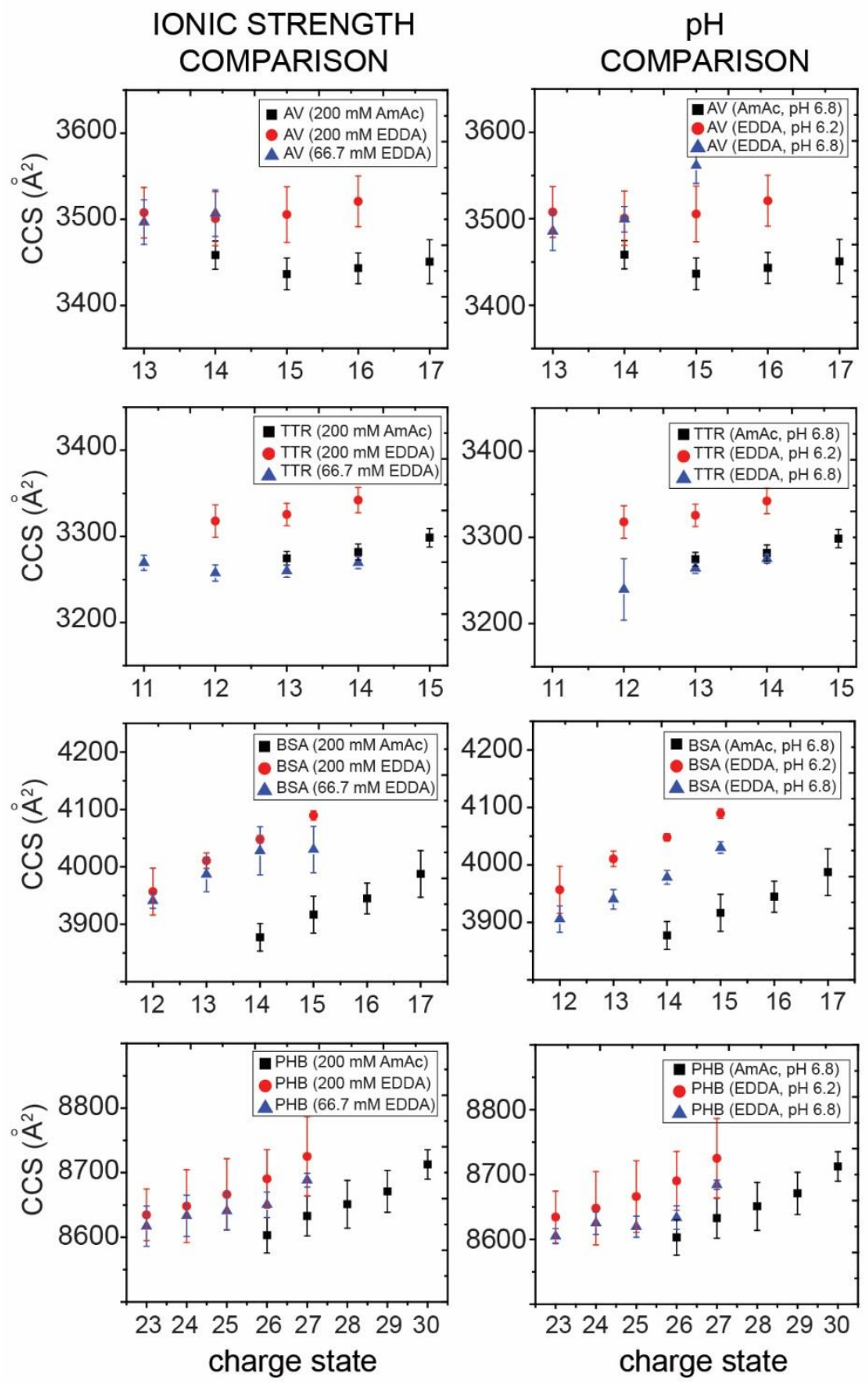

Figure S2. Impact of ionic strength and $\mathrm{pH}$ on CCS values for overlapping charge states using AmAc and EDDA solution conditions. EDDA was adjusted for either ionic strength (top row) or $\mathrm{pH}$ (bottom row) compared with database conditions. Black data points indicate AmAc ${ }^{\mathrm{DT} C C S_{\mathrm{He}}}$ values included within this database (200 mM AmAc, $200 \mathrm{mM}$ total ionic strength, pH 6.8). Red data points indicate EDDA ${ }^{\mathrm{DT}} \mathrm{CCS}_{\mathrm{He}}$ values included within this database (200 mM EDDA, 600 $\mathrm{mM}$ total ionic strength, $\mathrm{pH}$ 6.2). Blue data points indicate EDDA ${ }^{\mathrm{DT}} \mathrm{CCS} \mathrm{He}_{\mathrm{He}}$ values under solution conditions that have been adjusted from the database preparation procedure to account for ionic strength of EDDA: $66.7 \mathrm{mM}$ (200 mM total ionic strength) (top row) or $\mathrm{pH}: 6.8$, adjusted with ethylenediamine (bottom row). Error bars indicate standard deviation values for CCS values run in triplicate. All errors are $\leq 1.0 \%$ of the mean CCS. 

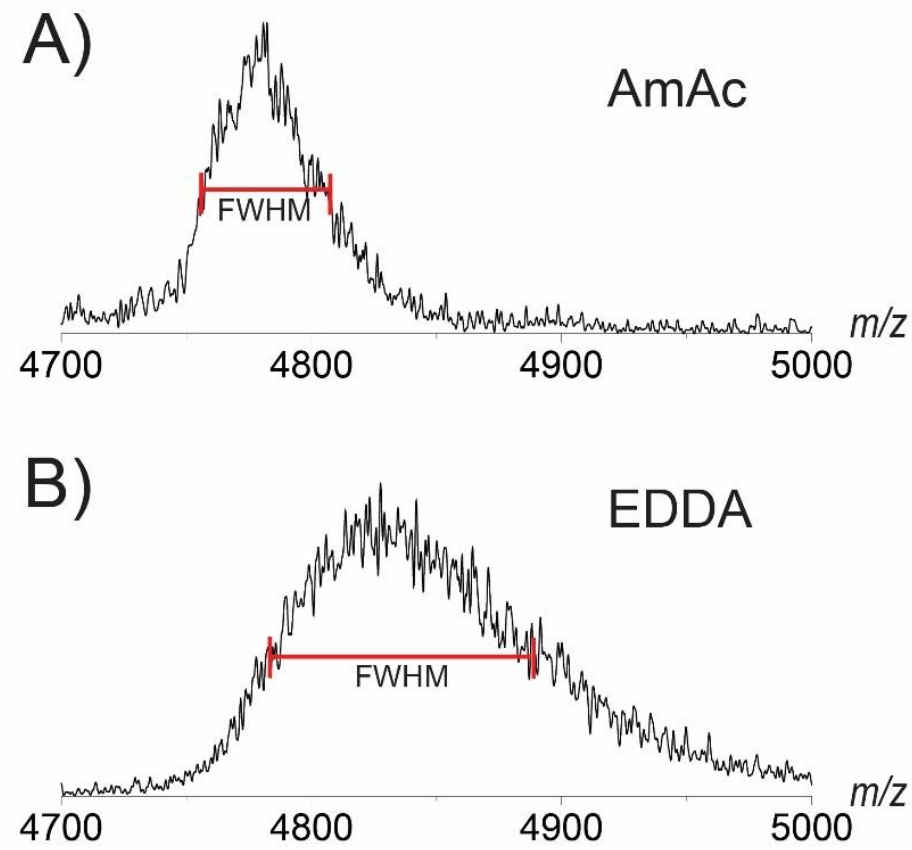

Figure S3. Representative mass spectrum of the 14+ charge state of bovine serum albumin using A) AmAc solution conditions (200 mM, $200 \mathrm{mM}$ ionic strength, $\mathrm{pH}$ 6.8) and B) EDDA solution conditions (200 mM, $600 \mathrm{mM}$ ionic strength, pH 6.2). A Savitzky Golay smooth was performed on both spectra here (number of smooths $=15$, smooth window channels $=15$ ). Calculating and averaging the FWHM of the $\mathrm{m} / \mathrm{z}$ peak width (for BSA, TTR, AV, and PHB) shows that EDDA peaks are $1.6 \pm 0.4$ times those of their AmAc counterparts. Interrogating these proteins in which ${ }^{1 r y, D T} \mathrm{CCS}$ values of the overlapping charge states resulted in ${ }_{1 \mathrm{ry}, \mathrm{DT}} \mathrm{CCS}(\mathrm{EDDA})>{ }^{1 \mathrm{ry}, \mathrm{DT}} \mathrm{CCS}(\mathrm{AmAc})$ indicates effects from $\mathrm{pH}$ and ionic strength (main text Figure 4) and salt adducts as illustrated here. 


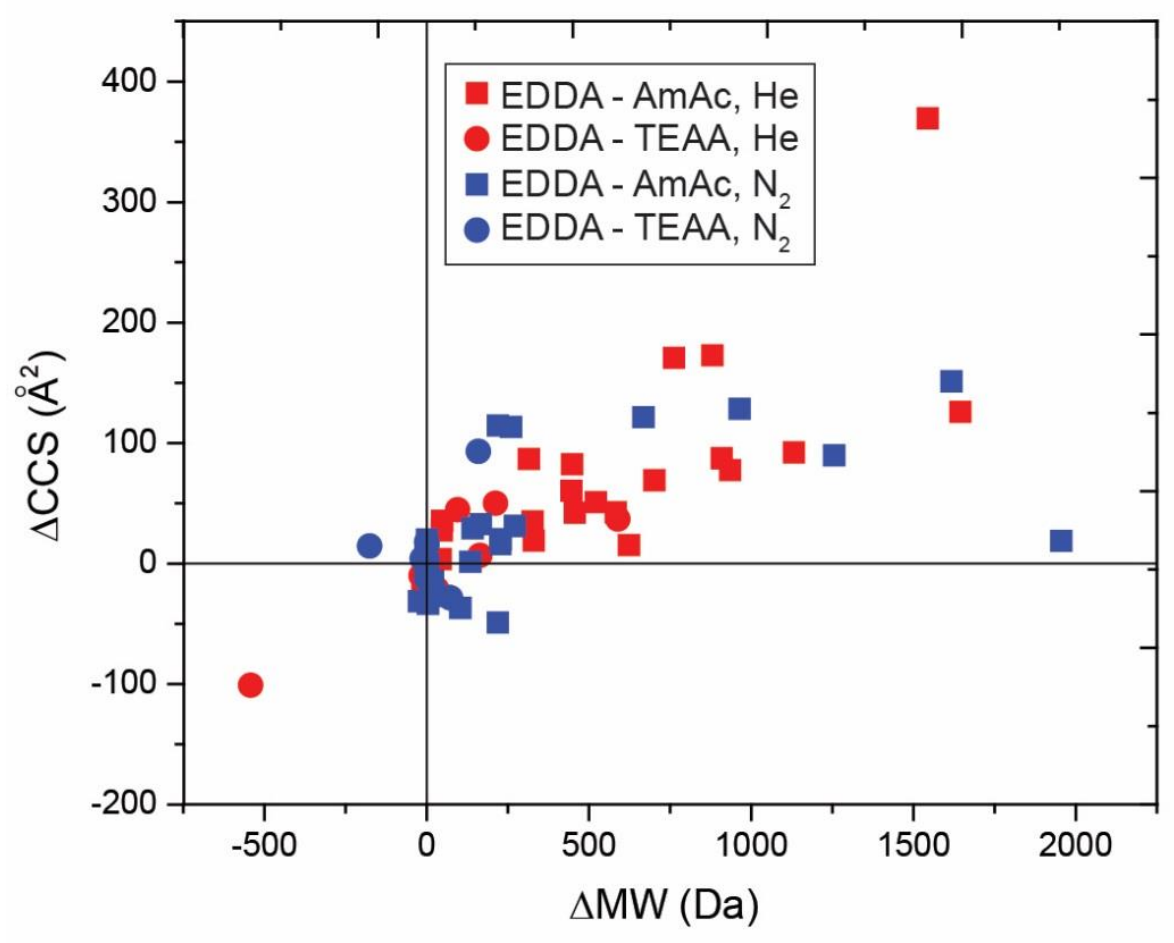

Figure S4. Differences in experimentally observed molecular weight between overlapping charge states of different solution conditions were typically positively correlated with differences in CCS. The extent of adduction (increasing MW) can impact the volume of a protein in the gas phase, as reflected by the observed CCS. This trend held true for overlapping charge states between EDDA and AmAc solution conditions (square data points) and overlapping charge states between EDDA and TEAA solution conditions (circle data points) in both drift gases (He in red, $\mathrm{N}_{2}$ in blue). Typically, EDDA provided a greater number of adducts than AmAc or TEAA, although this was protein dependent (e.g. CRP, as represented by the most lower left data point had greater adducts with TEAA than EDDA). Other differences between solution conditions such as $\mathrm{pH}$ and ionic strength can also have an impact on the observed CCS, as discussed in the main text. 


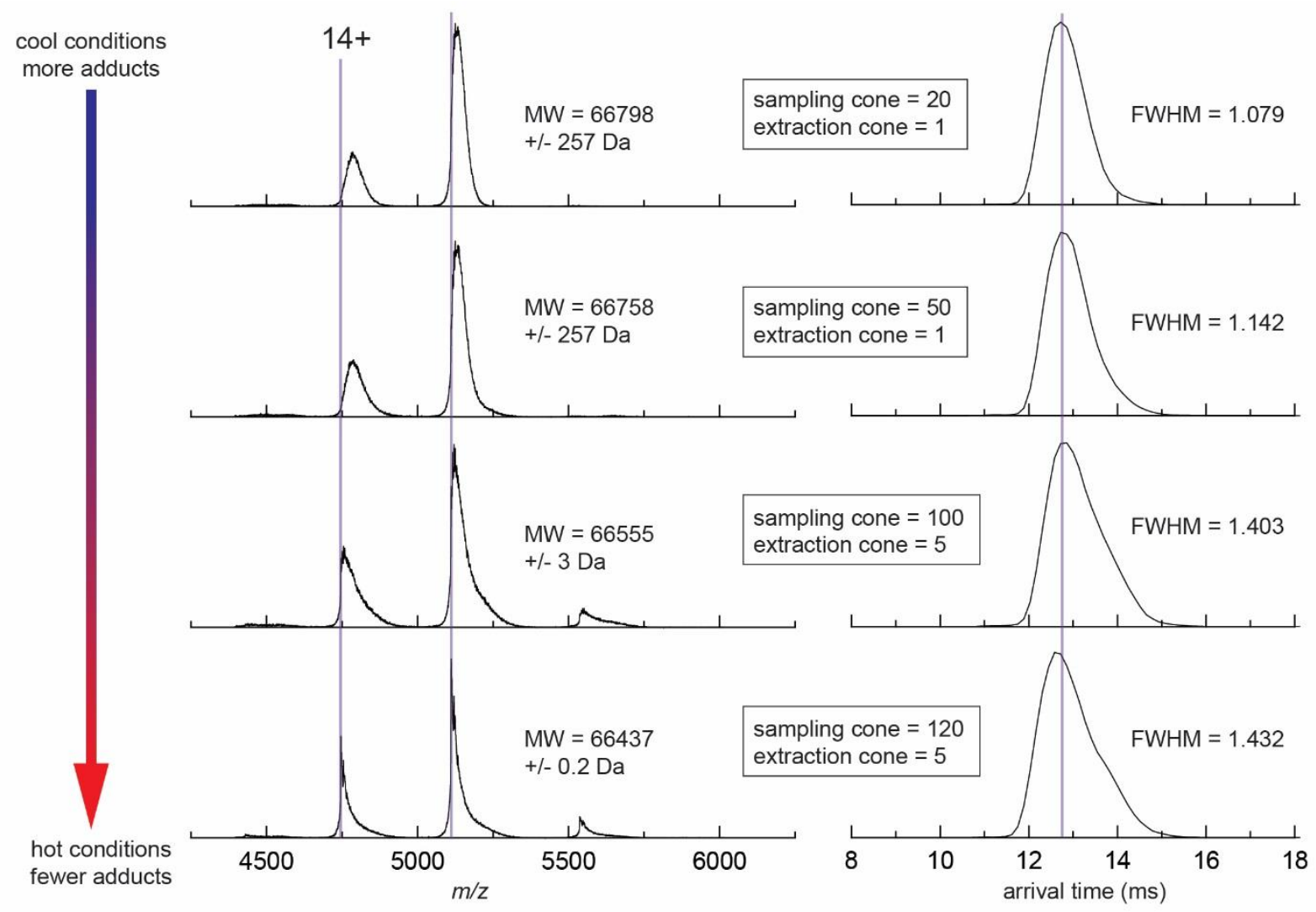

Figure S5. Mass spectra (left) and corresponding arrival time distributions (right) of bovine serum albumin in EDDA (200 mM, $600 \mathrm{mM}$ ionic strength, $\mathrm{pH}$ 6.2). ATDs were extracted from the $14+$ charge state of BSA, spanning the $\mathrm{m} / \mathrm{z}$ range of 4,720 to 4,920 . Increasing the sampling and extraction cone voltage to remove adducts resulted in a cleaner protein more similar to AmAc experiments but caused restructuring as evidenced by the arrival time distribution. The ATD width increases with increasing source activation (decrease in adducts). If the ATD shift was solely due to adduct removal, the width of the ATD would be expected to narrow accordingly as the ion population becomes more homogeneous in mass. 


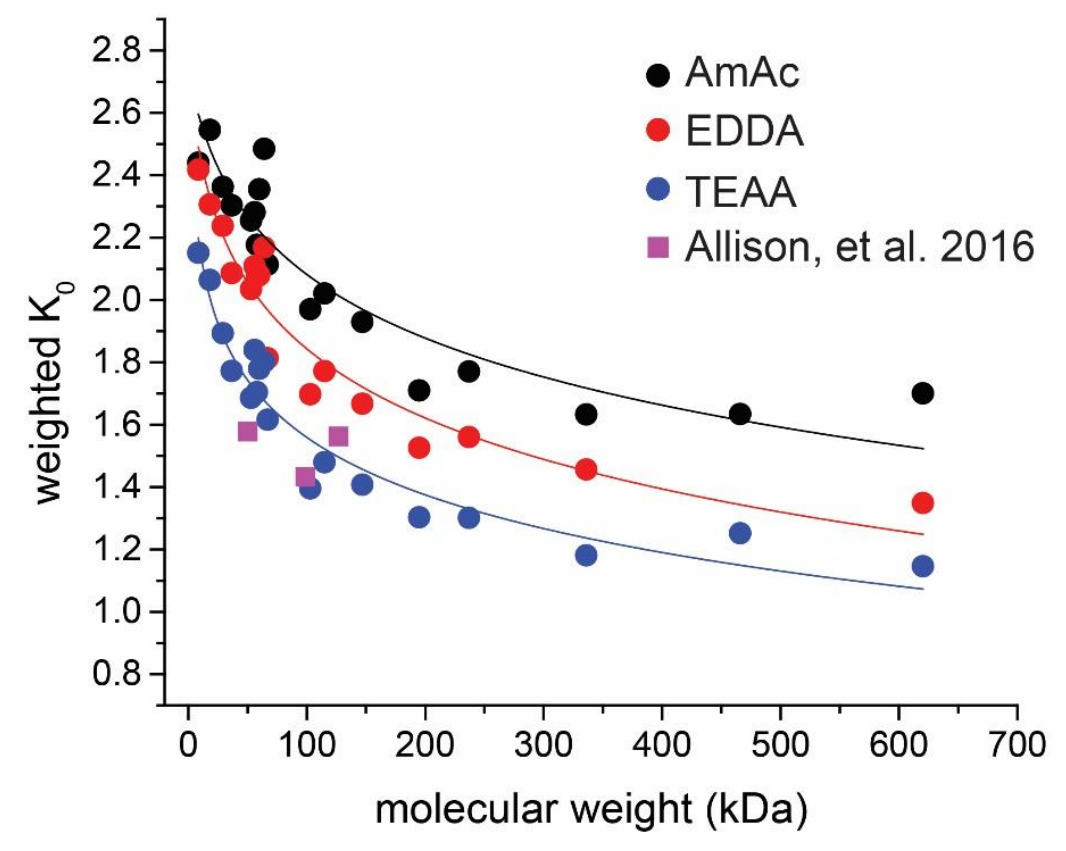

Figure S6. Reduced mobility $\left(\mathrm{K}_{0}\right)$ vs. molecular weight for three different solution conditions: normal-charge AmAc (black), reduced-charge EDDA (red), and reduced-charge TEAA (blue) in $\mathrm{He}$ drift gas. Single mobility values for each protein are plotted for simplicity. These were calculated by weighting the mobility value of each charge state with the integrated charge state area from the collected mass spectrum. Unweighted average mobility values of standard membrane proteins in C8E4 detergent as utilized by Allison, et al. $(2016)^{27}$ and obtained from prior DTIMS ${ }^{28,46}$ experiments are plotted in purple for comparison. The best-fit in these plots is included to guide the eye. 


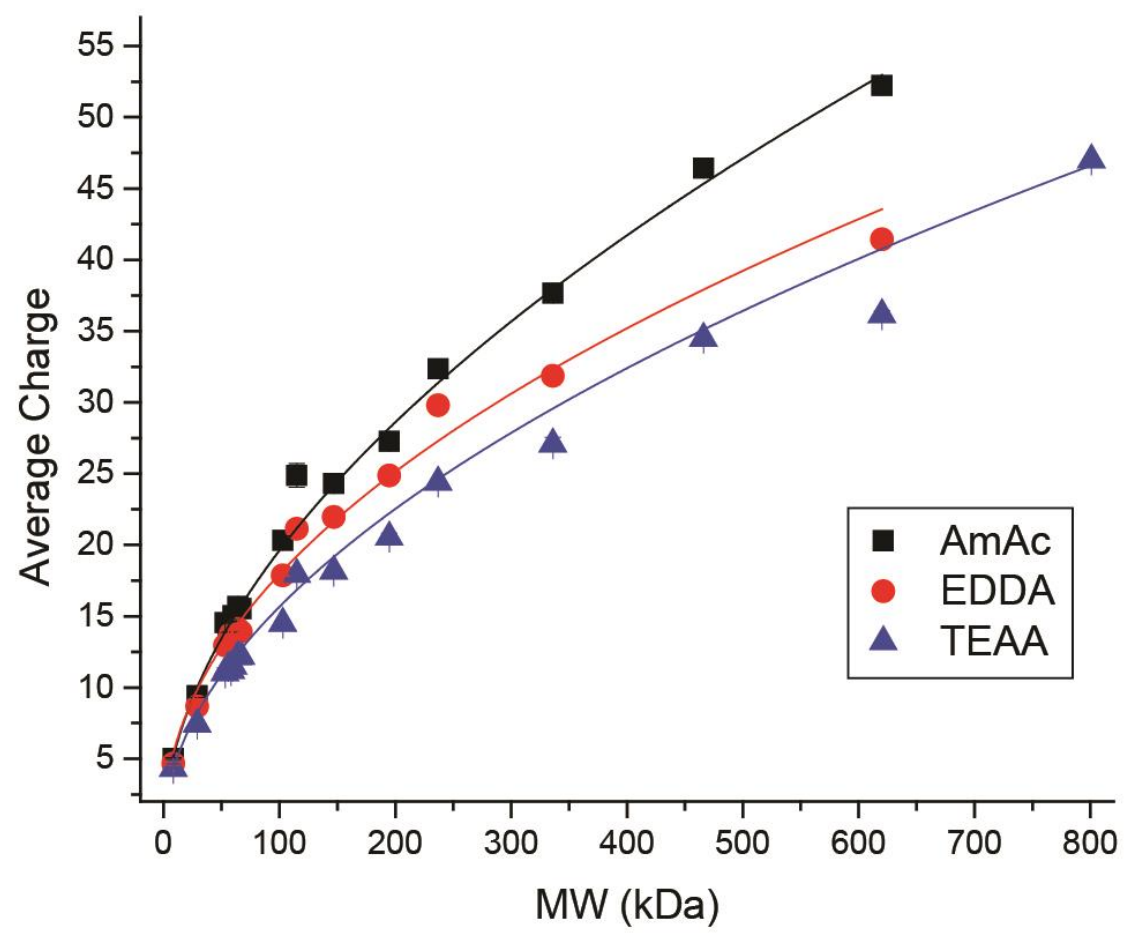

Figure S7. Average charge vs. molecular weight for all proteins and protein complexes generated for this CCS database in $\mathrm{N}_{2}$ drift gas. The mass spectrum of a protein with unknown CCS or mobility can be used to compare with this figure in selecting appropriate mobilitymatched calibrants. Trendlines are used to guide the eye.

\section{TWIM calibration experiments testing the need to "mobility-match" calibrants and unknowns:}

In the data shown within Figure S8 and S9, $\beta$-lactoglobulin A (monomer), carbonic anhydrase, streptavidin, cholera toxin $B$, and neutravidin were chosen as the calibrants for TWIM experiments. $\beta$-lactoglobulin $A$ (dimer) and transthyretin were treated as independent unknowns; during calculations in which $\beta$-lactoglobulin $A$ (dimer) was the unknown, transthyretin was incorporated as an additional calibrant protein and vice versa. 


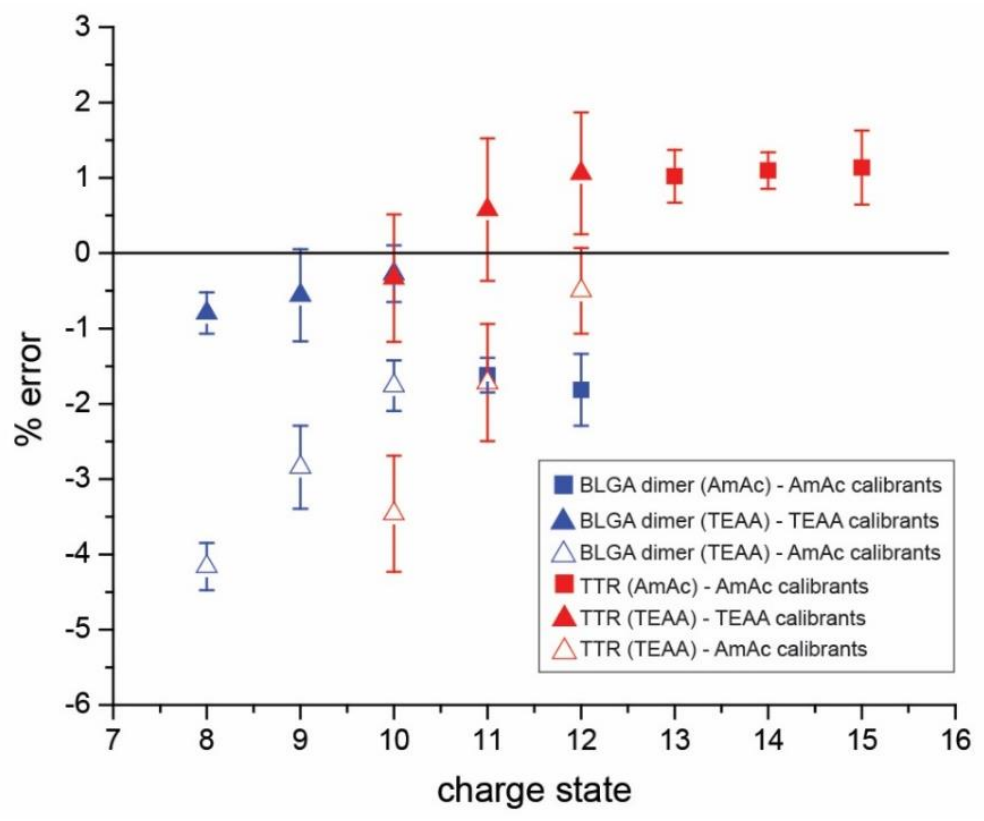

Figure S8. Percent error in CCS values obtained from calibrated TWIM experiments for $\beta$ lactoglobulin dimer (blue, BLGA, $36 \mathrm{kDa}$ ) and transthyretin (red, TTR, $56 \mathrm{kDa}$ ) "unknowns" when compared to CCS values obtained from first principles within this work. Using calibrant solution/charge conditions that match that of the calibrant (closed data points) affords much lower error in CCS than using calibrant solution/charge conditions that do not match that of the calibrant (open data points).

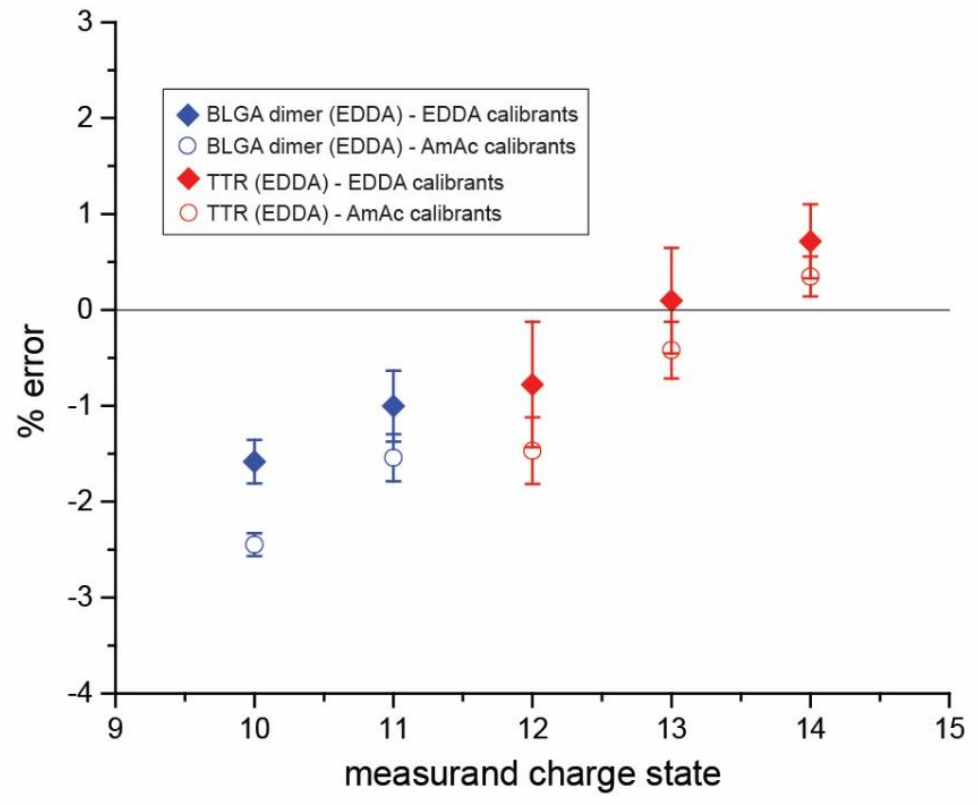

Figure S9. Error in CCS values obtained from a TWIM calibration for $\beta$-lactoglobulin dimer (blue, BLGA, $36 \mathrm{kDa}$ ) and transthyretin (red, TTR, $56 \mathrm{kDa}$ ) "unknowns" when compared to CCS values obtained from first principles within this work. Bracketing only molecular weight but using differing solution conditions (open data points) resulted in greater CCS error, though less pronounced than with TEAA "unknowns" and AmAc calibrants as in Figure S8. Because EDDA results in less strongly charge-reduced ions when compared with TEAA, the calibrants more closely bracket the mobilities of the unknowns compared in this case. 
Table S10. Proteins used as calibrants for narrow and wide TWIM CCS calibrations as shown in Figure S9. "Unknown" proteins (top row) were calibrated with both "narrow" calibrant selection (i.e. those that match the mobility values most closely) or "wide" calibrant selection (i.e. a wider range of mobility values). Both narrow and wide calibrant selections properly bracketed the mobility values of the "unknown" protein, affording multiple data points with both lower and higher mobilities. Proteins are organized by molecular weight but streptavidin typically has slightly lower mobility values than transthyretin.

\begin{tabular}{c|c|c|c|c|c|c}
\hline & $\begin{array}{c}\text { SA } \\
\text { (narrow) }\end{array}$ & $\begin{array}{c}\text { SA } \\
\text { (wide) }\end{array}$ & $\begin{array}{c}\text { ConA } \\
\text { (narrow) }\end{array}$ & $\begin{array}{c}\text { ConA } \\
\text { (wide) }\end{array}$ & $\begin{array}{c}\text { CRP } \\
\text { (narrow) }\end{array}$ & $\begin{array}{c}\text { CRP } \\
\text { (wide) }\end{array}$ \\
\hline \hline CA & $\mathrm{X}$ & $\mathrm{X}$ & & $\mathrm{X}$ & & $\mathrm{X}$ \\
\hline SA & & & & $\mathrm{X}$ & & $\mathrm{X}$ \\
\hline TTR & $\mathrm{X}$ & $\mathrm{X}$ & & $\mathrm{X}$ & & $\mathrm{X}$ \\
\hline NAV & $\mathrm{X}$ & & $\mathrm{X}$ & & $\mathrm{X}$ & \\
\hline BSA & $\mathrm{X}$ & & $\mathrm{X}$ & & $\mathrm{X}$ & \\
\hline ConA & $\mathrm{X}$ & & & & $\mathrm{X}$ & \\
\hline CRP & & $\mathrm{X}$ & $\mathrm{X}$ & & & \\
\hline ADH & & $\mathrm{X}$ & $\mathrm{X}$ & $\mathrm{X}$ & $\mathrm{X}$ & $\mathrm{X}$ \\
\hline PHB & & $\mathrm{X}$ & $\mathrm{X}$ & $\mathrm{X}$ & $\mathrm{X}$ & $\mathrm{X}$ \\
\hline
\end{tabular}


Figure S10. Representative mass spectra for each protein: *note that relative intensities between charge states may vary slightly with nanoelectrospray tip and tip position. Instrument parameters were carefully controlled to minimize ion activation resulting in broader peaks.

Representative charge states in each plot are labeled for reference.

UBIQUITIN (UB):

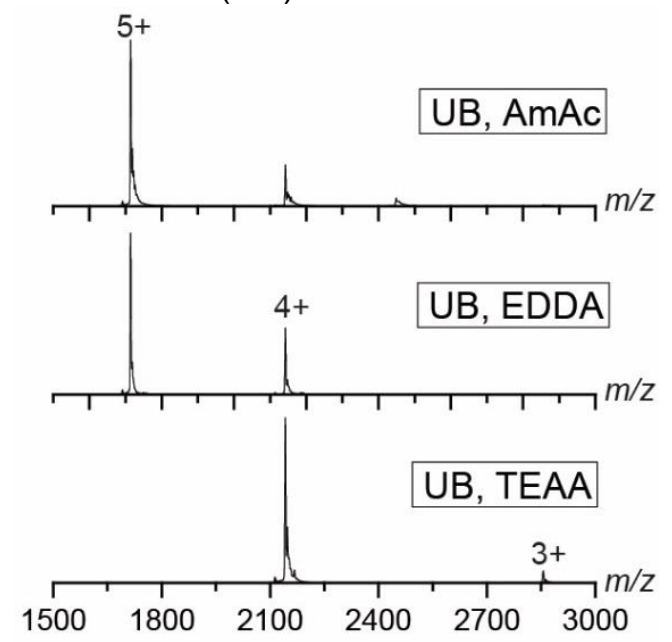

B-LACTOGLOBULIN A (BLGA):

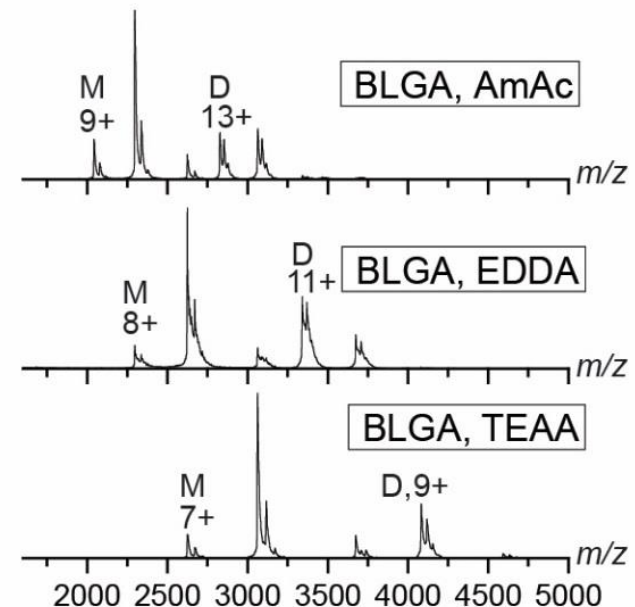

CARBONIC ANHYDRASE (CA):

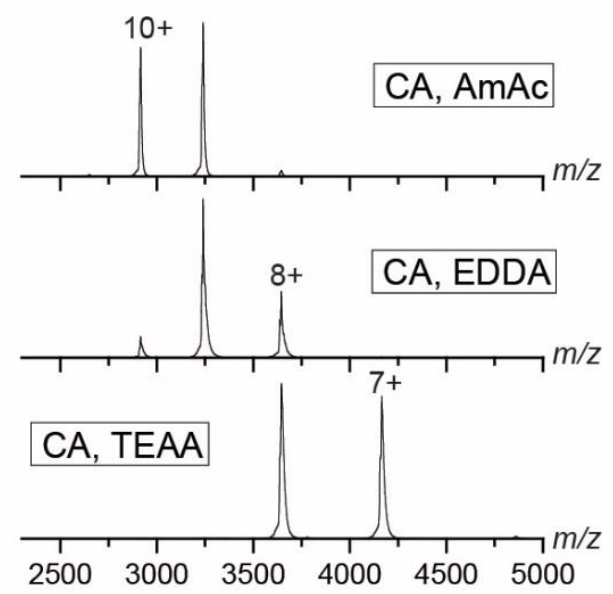

STREPTAVIDIN (SA):
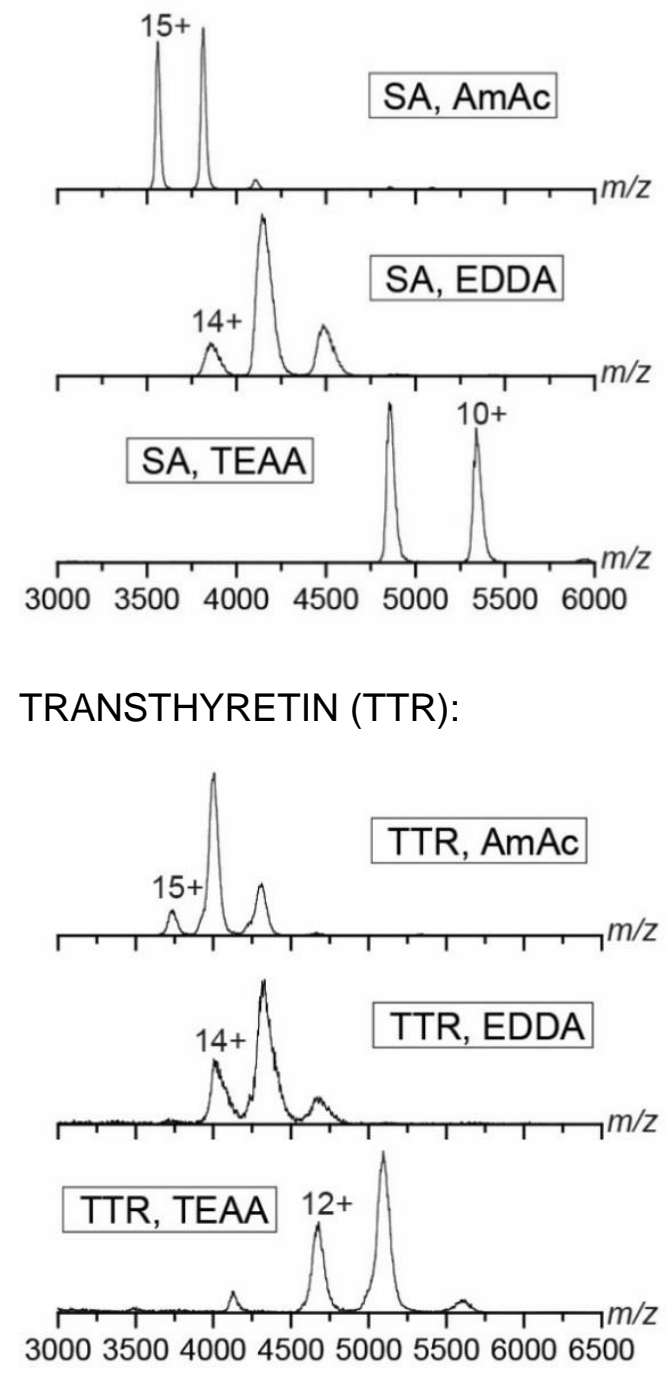

CHOLERA TOXIN B (CTB):

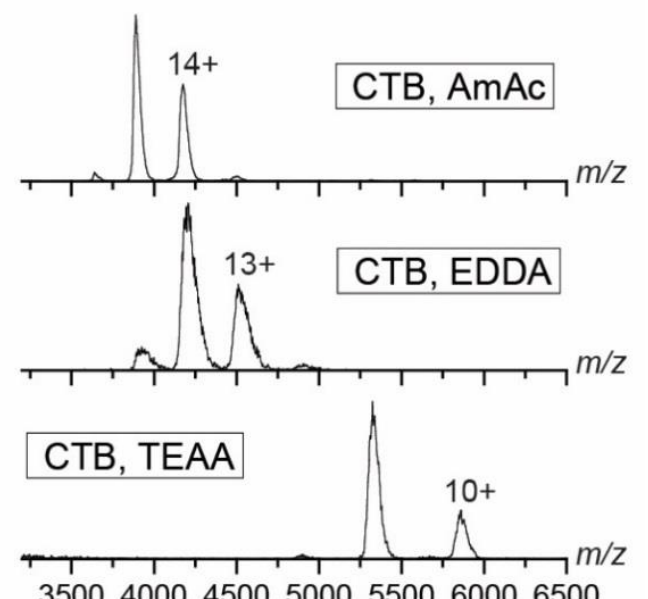


NEUTRAVIDIN (NAV):

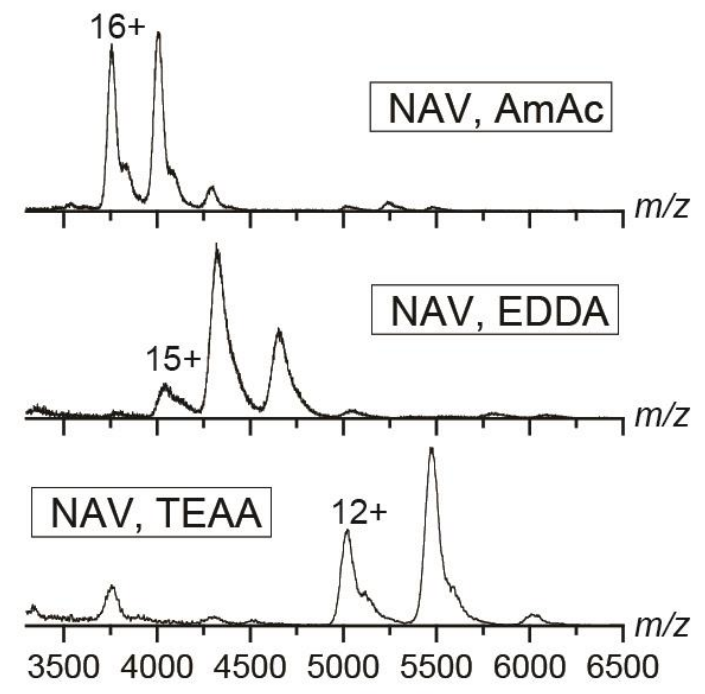

AVIDIN (AV):
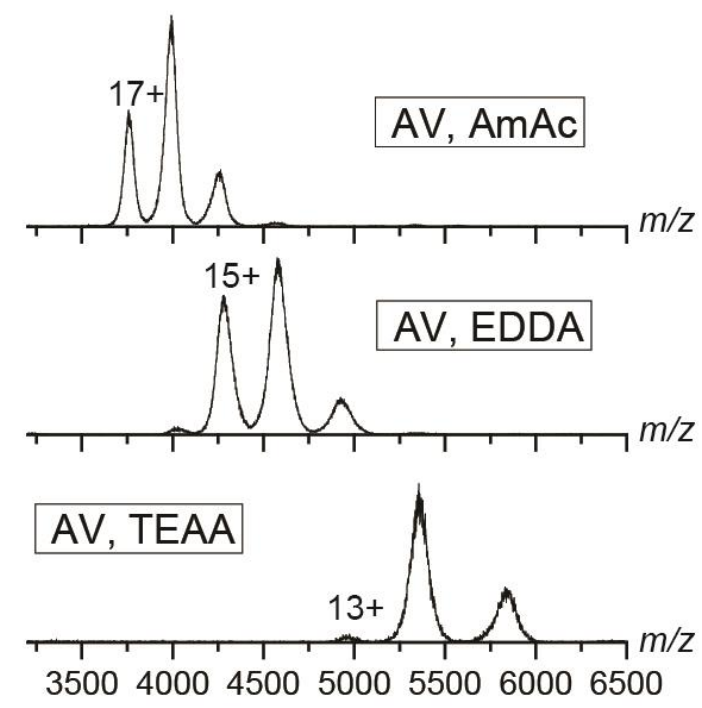

BOVINE SERUM ALBUMIN (BSA):

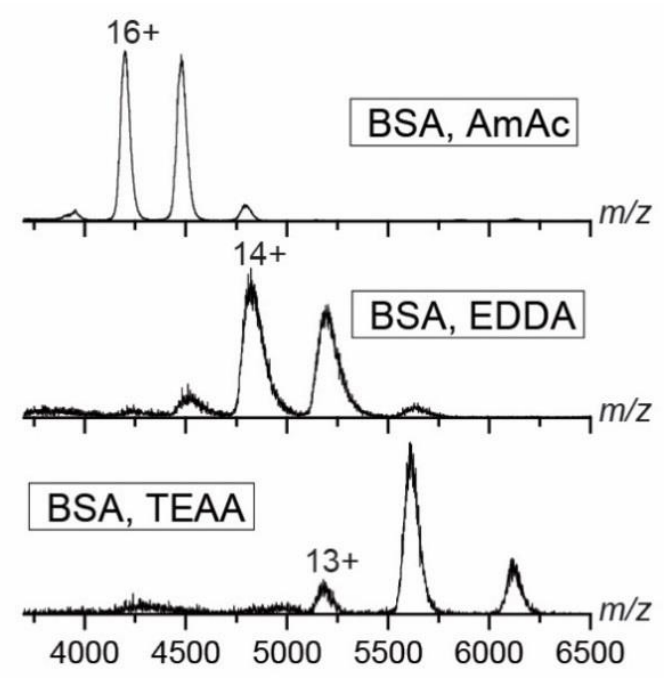

CONCANAVALIN A (CONA):

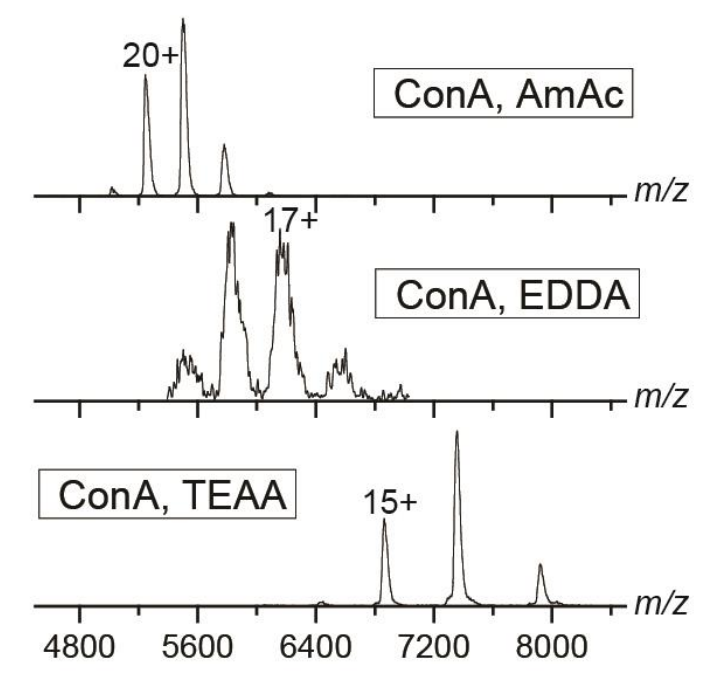

C-REACTIVE PROTEIN (CRP):

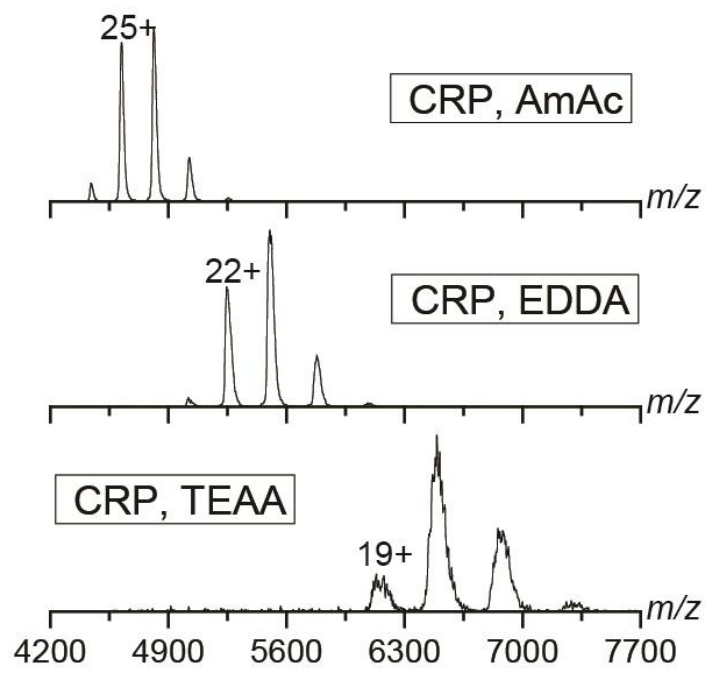

ALCOHOL DEHYDROGENASE (ADH):

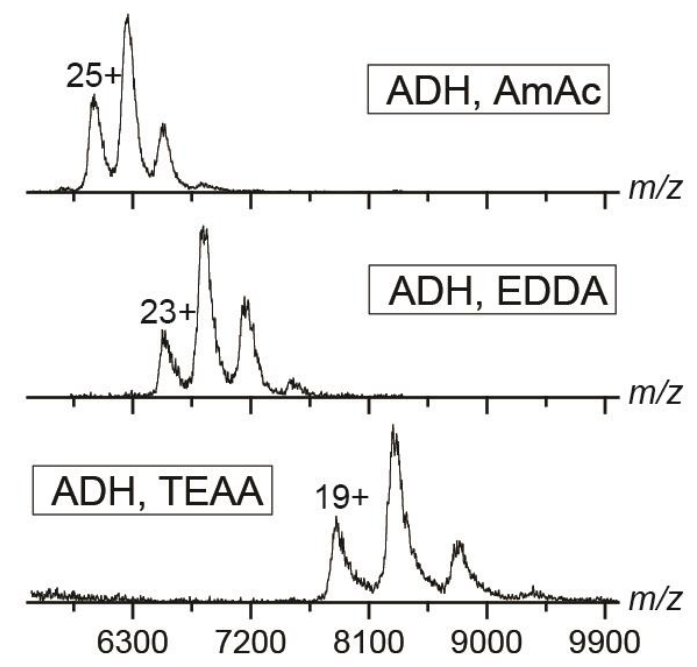


PHOSPHORYLASE B (PHB):
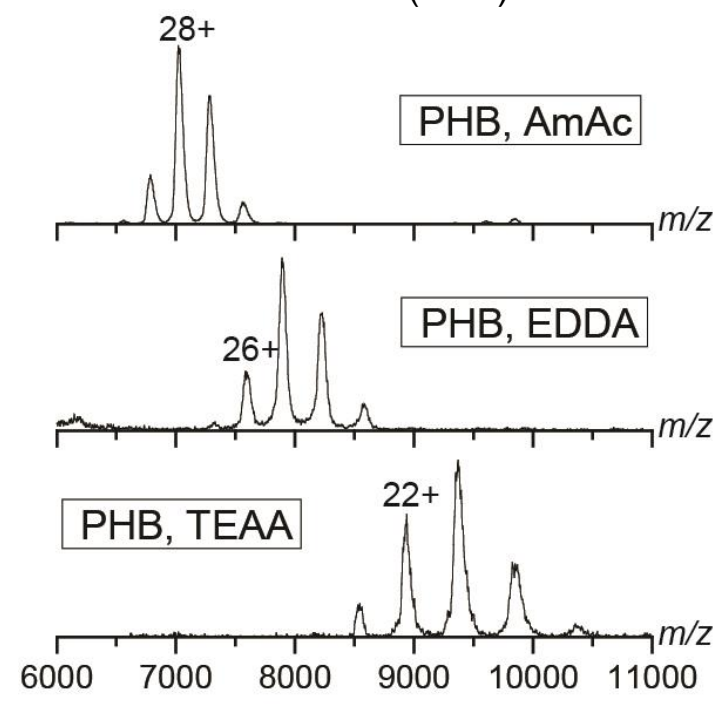

PYRUVATE KINASE (PK):

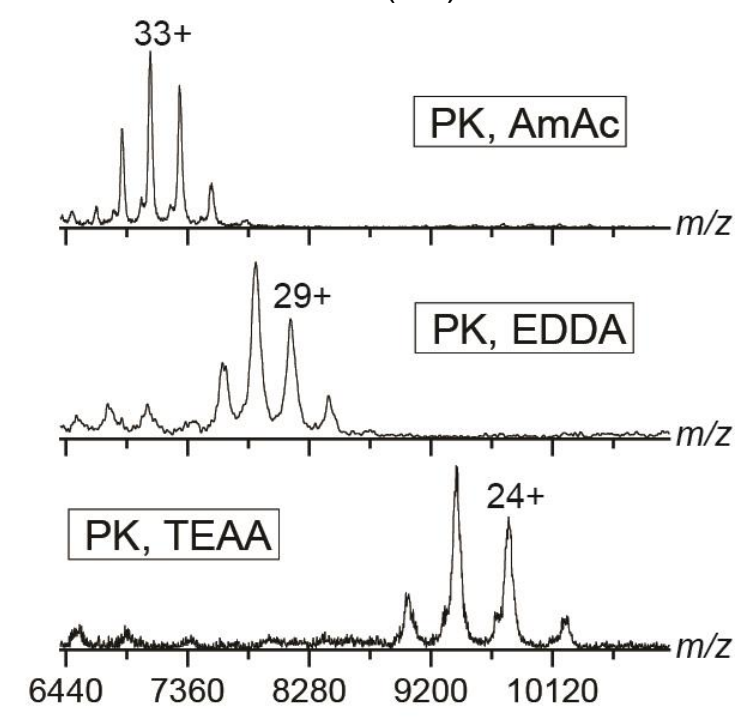

GLUTAMATE DEHYDROGENASE (GDH):

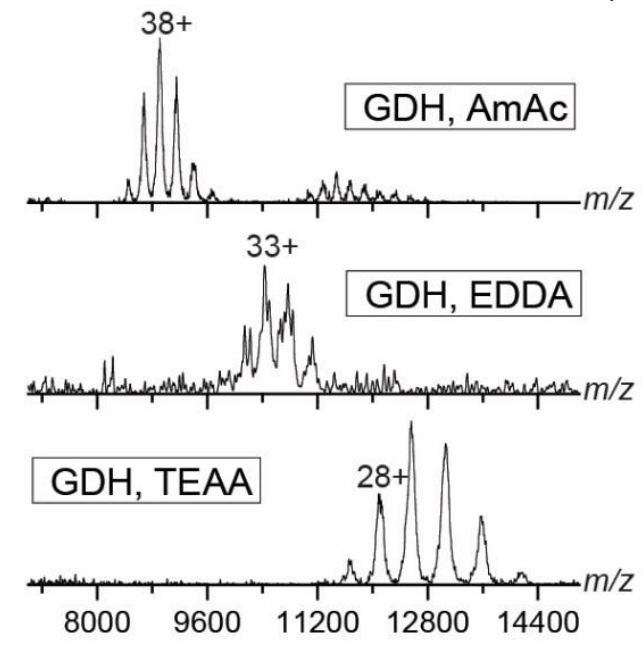

B-GALACTOSIDASE (B-GAL):

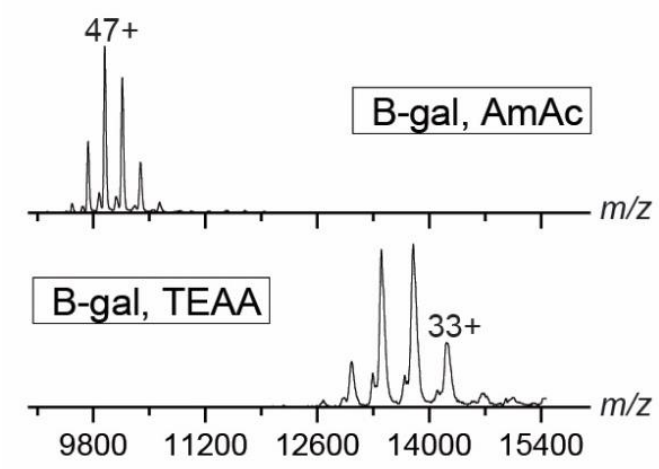

\section{GLUTAMINE SYNTHETASE (GS):}

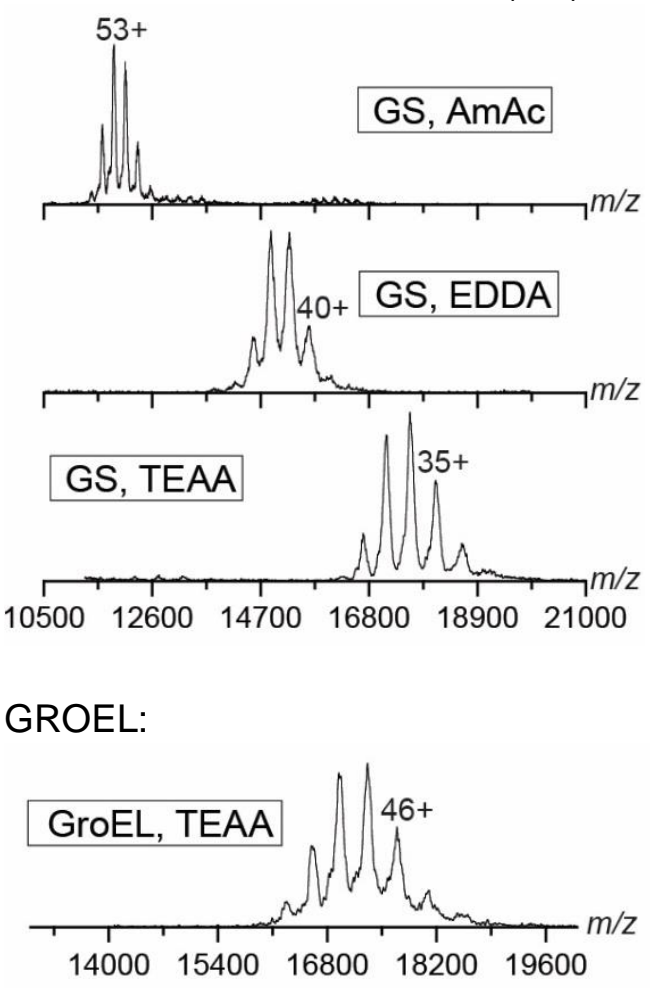


Matlab script used for linear field drift cell experiment calculations:

User input: experimental molecular weight, drift gas mass, experimental temperature, charge state, .CSV file name, output file name

Matlab output: $\mathrm{R}^{2}$ of best-fit line, centroid of Gaussian fit for each bias(drift voltage), $\mathrm{K}_{0}, \mathrm{CCS}$, list of input parameters

Required input file: .CSV file containing the ion mobility bias value, experimentally-recorded pressure (in torr) at each bias (drift voltage), arrival time distribution. Example below.

TWIMExtract ${ }^{1}$ software results in output of the arrival time and intensity in the format shown.

\begin{tabular}{|c|c|c|c|c|c|c|c|c|c|c|c|}
\hline \multirow{14}{*}{$\begin{array}{c}\text { arrival } \\
\text { time }\end{array}$} & 4 & A & B & C & D & $\mathrm{E}$ & $\mathrm{F}$ & G & $\mathrm{H}$ & \multirow{2}{*}{$\begin{array}{r}80 \\
\end{array}$} & \multirow{14}{*}{$\begin{array}{l}\longleftarrow \text { IM bias } \\
\longleftarrow \text { pressure (torr) }\end{array}$} \\
\hline & 1 & & 10 & 20 & 30 & 40 & 50 & 60 & 70 & & \\
\hline & 2 & & 1.306486 & 1.306296 & 1.306074 & 1.305926 & 1.305888 & 1.305812 & 1.30566 & 1.305622 & \\
\hline & 3 & 0.1373 & 0 & 0 & 0 & 0 & 0 & 0 & 0 & 0 & \\
\hline & 4 & 0.2746 & 0 & 0 & 0 & 0 & 0 & 0 & 0 & 0 & \\
\hline & 5 & 0.4119 & 0 & 0 & 0 & 0 & 0 & 0 & 0 & 0 & \\
\hline & 6 & 0.5492 & 0 & 0 & 0 & 0 & 0 & 0 & 0 & 0 & \\
\hline & 7 & 0.6865 & 0 & 0 & 0 & 0 & 0 & 0 & 0 & 0 & \\
\hline & 8 & 0.8238 & 0 & 0 & 0 & 0 & 0 & 0 & 0 & 0 & \\
\hline & 9 & 0.9611 & 0 & 0 & 0 & 0 & 0 & 0 & 0 & 0 & \\
\hline & 10 & 1.0984 & 0 & 0 & 0 & 0 & 0 & 0 & 0 & 0 & \\
\hline & 11 & 1.2357 & 0 & 0 & 0 & 0 & 0 & 0 & 0 & 0 & \\
\hline & 12 & 1.373 & 0 & 0 & 0 & 0 & 0 & 0 & 0 & 0 & \\
\hline & 13 & 1.5103 & 0 & 0 & 0 & 0 & 0 & 0 & 0 & 0 & \\
\hline
\end{tabular}

Within the CCS calculation portion of the Matlab script, constants from the Mason-Schamp equation were combined into one "factor". The calculation to determine this factor is shown below and includes adjustments for unit conversion (i.e. converting $\mathrm{cm}^{2}$ to $\mathrm{m}^{2}$ within the $\mathrm{K}_{0}$ input value, converting $\mathrm{g} / \mathrm{mol}$ to $\mathrm{kg}$ for the reduced-mass value, converting the final CCS from $\mathrm{m}^{2}$ to $\AA^{2}$, etc.).

$$
\begin{gathered}
C C S=\frac{3 e z}{16 N_{0}} \sqrt{\frac{2 \pi}{\mu k_{B} T}} \frac{1}{K_{0}} \\
C C S=\frac{3 \cdot 1.602 \cdot 10^{-19}}{16 \cdot 2.687 \cdot 10^{25}} \cdot \sqrt{\frac{2 \pi \cdot 1000 \cdot 6.022 \cdot 10^{23}}{1.3806 \cdot 10^{-23}}} \cdot 10^{24} \cdot\left(z \sqrt{\frac{1}{\mu T}} \frac{1}{K_{0}}\right) \\
C C S=18508 \cdot\left(z \sqrt{\frac{1}{\mu T}} \frac{1}{K_{0}}\right)
\end{gathered}
$$

Units are not included here for simplicity but use of this combined factor holds true where CCS output is in $\AA^{2}, \mathrm{~K}_{0}$ input is in $\mathrm{cm}^{2} / \mathrm{V} \cdot \mathrm{s}$, temperature input is in $\mathrm{K}$, and $\mu$ input is computed in Daltons.

Matlab script:

function [] = CCSCalc(Mass, Charge, Gas_Mass, Tk, File, OutputName)

\%File name should be as follows: 'example.csv'

o Output name should be in the following format

oprotein_gas_bufferconcentration_Buffer\#_charge

。 ex BSA $\overline{\mathrm{N}} 2$ 200 $\mathrm{mM}$ A 16

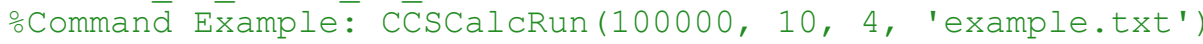




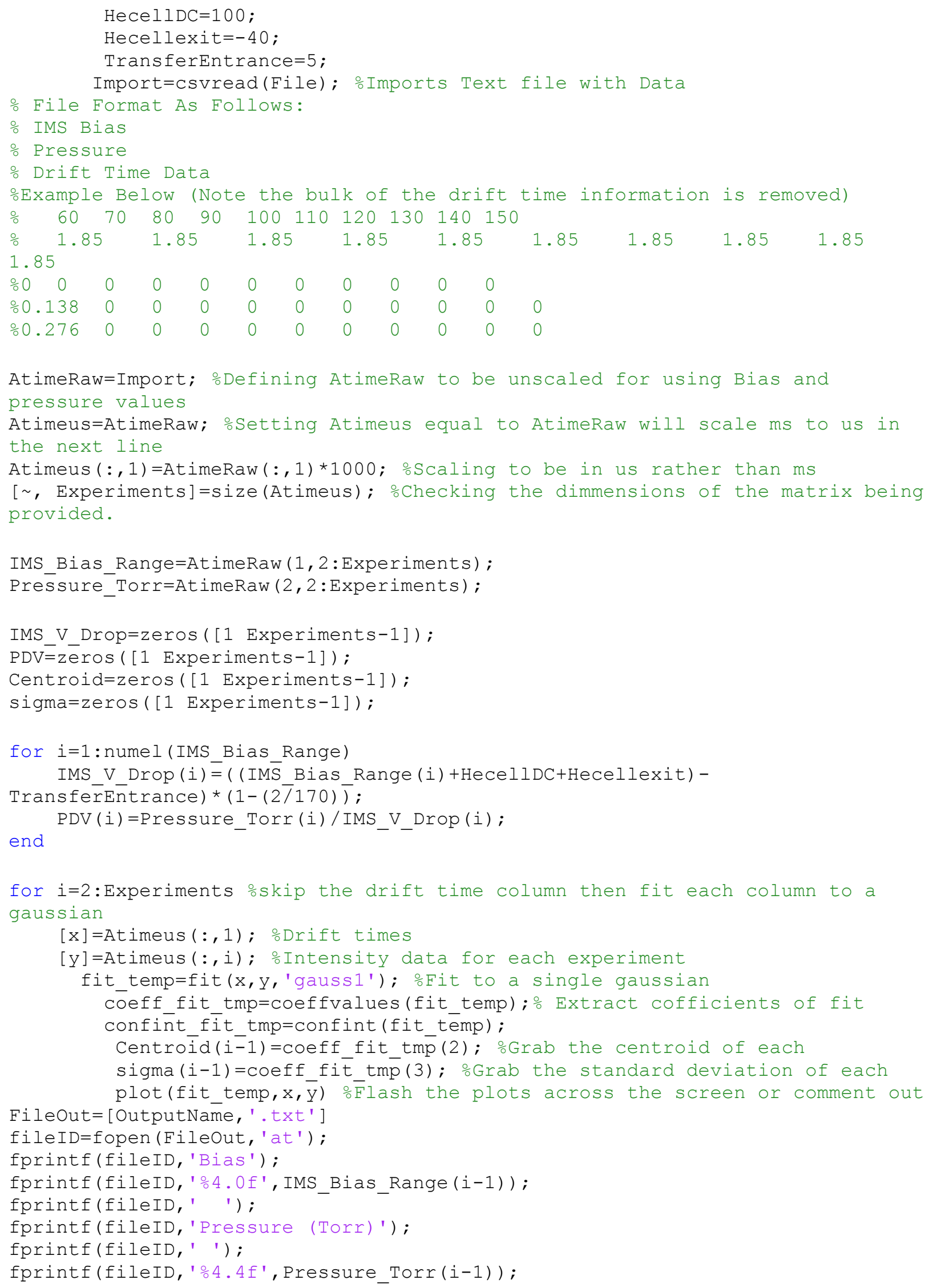




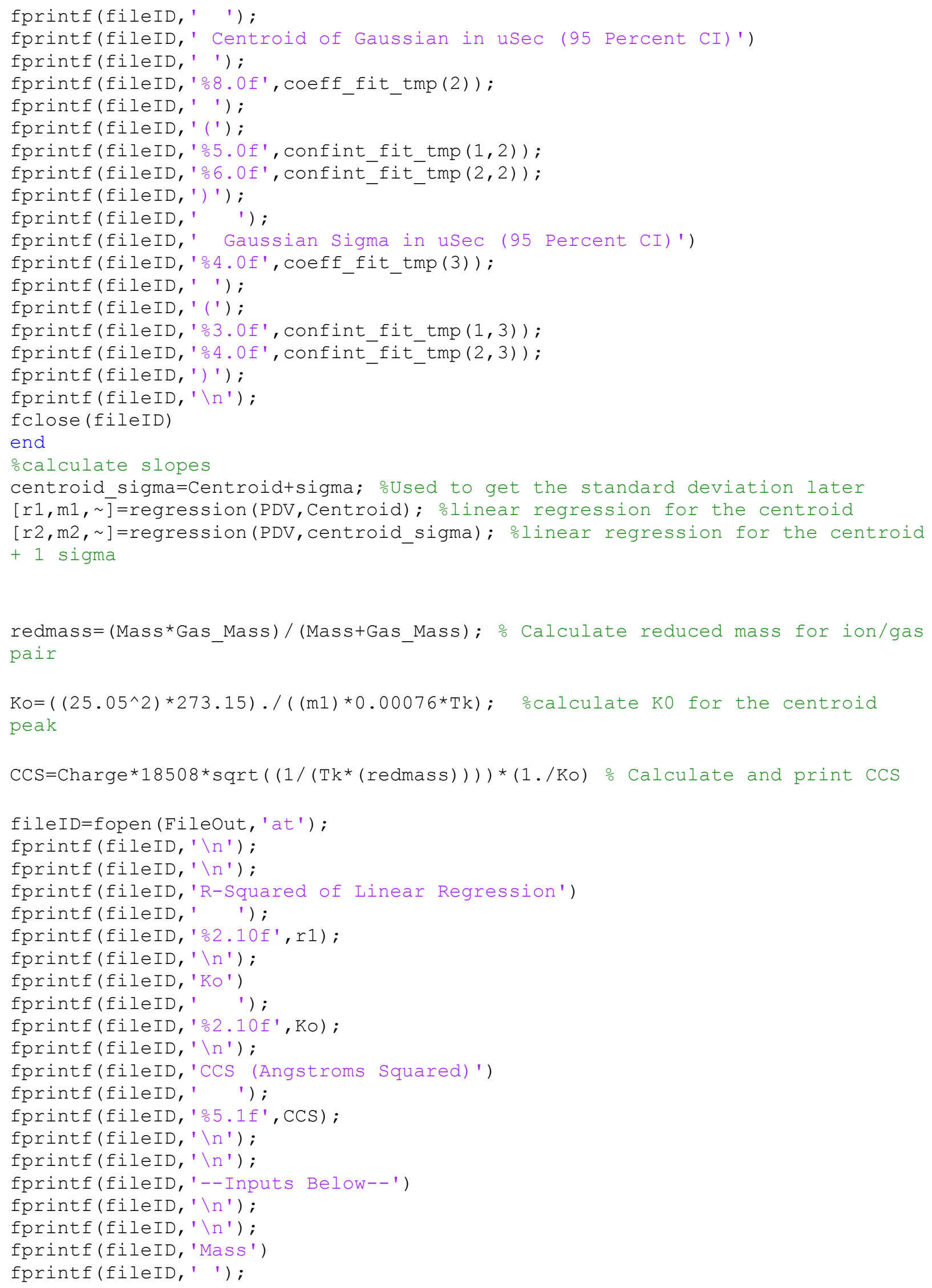




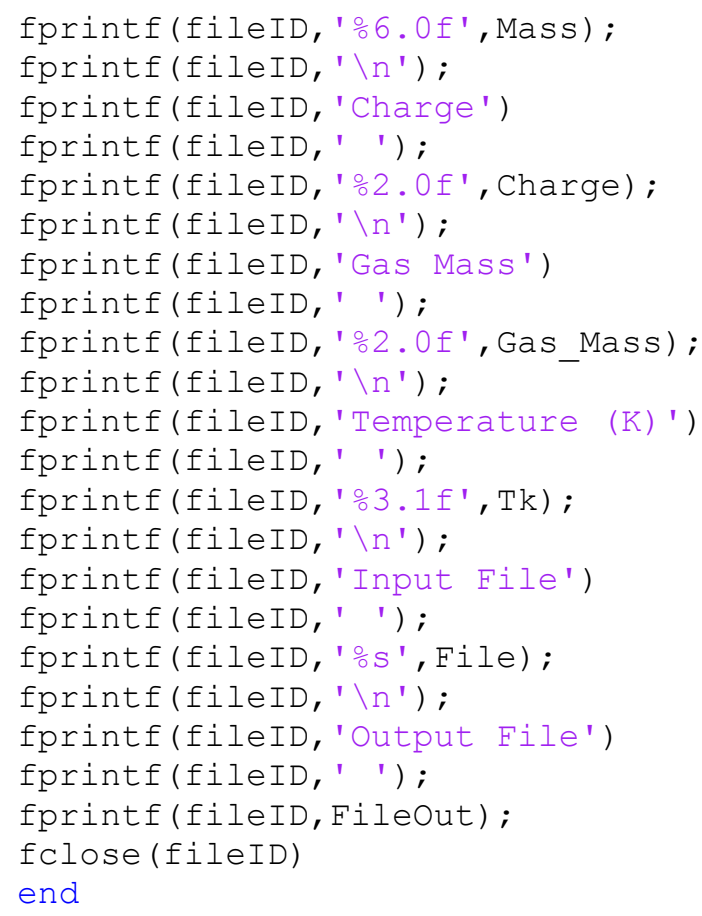

References:

(1) Haynes, S. E.; Polasky, D. A.; Dixit, S. M.; Majmudar, J. D.; Neeson, K.; Ruotolo, B. T.; Martin, B. R. Variable-Velocity Traveling-Wave Ion Mobility Separation Enhancing Peak Capacity for Data-Independent Acquisition Proteomics. Anal. Chem. 2017, 89 (11), 56695672. https://doi.org/10.1021/acs.analchem.7b00112.

(2) Gabelica, V.; Shvartsburg, A. A.; Afonso, C.; Barran, P. E.; Benesch, J. L. P.; Bleiholder, C.; Bowers, M. T.; Bilbao, A.; Bush, M. F.; Campbell, J. L.; et al. Recommendations for Reporting Ion Mobility Mass Spectrometry Measurements. Mass Spectrom. Rev. 2019, 9999, 1-30. https://doi.org/10.1002/mas.21585. 